\title{
Augmented Reality
}

\section{in Support of Industry 4.0}

\section{Implementation Challenges and Success Factors}

\author{
Tariq Masood and Johannes Egger \\ University of Cambridge
}
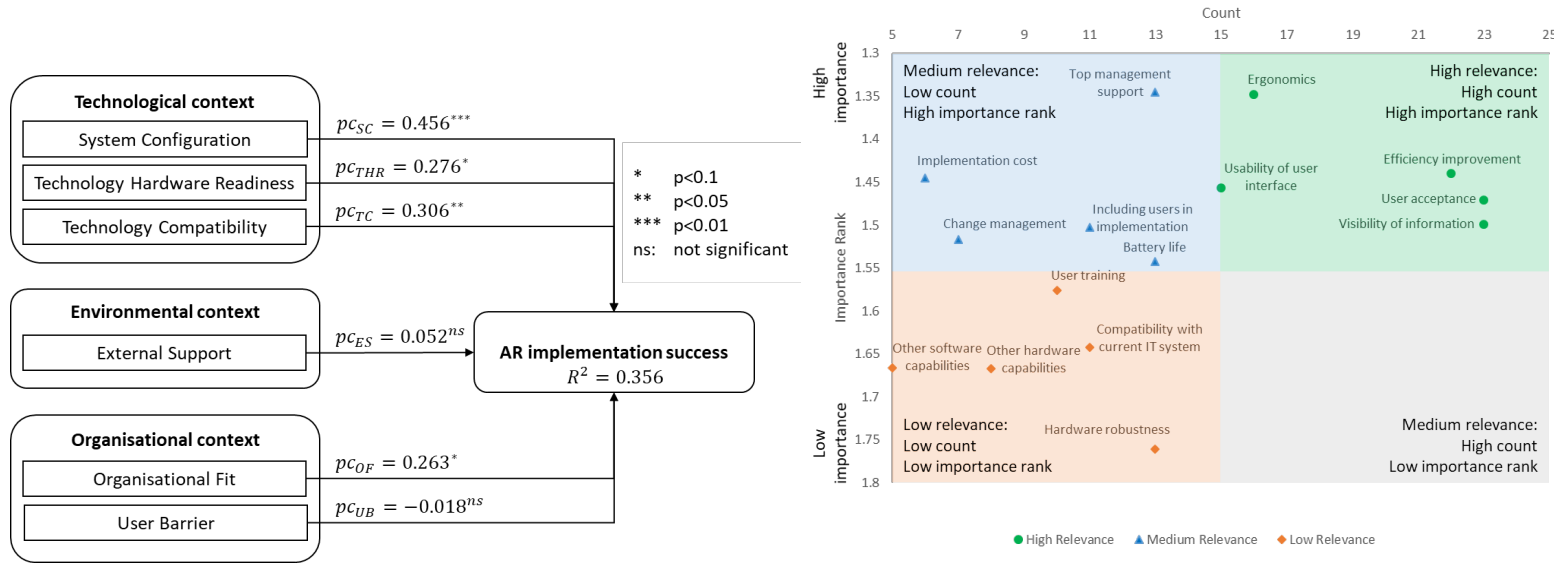

\section{Highlights}

- Industrial Augmented Reality (AR) is a central part of Industry 4.0 initiatives

- Providing guidance on which aspects industry should focus on to ensure AR implementation success

- Technology context and organisational fit are key success factors for the AR implementation

- User barrier and external support do not significantly influence the AR implementation success

- While technological aspects are important, organisational issues are more relevant for industry

Citation details: Masood, T. and Egger, J. (2019) 'Augmented Reality in support of Industry 4.0 - Implementation Challenges and Success Factors', Robotics and Computer Integrated Manufacturing, in press, pp. 1-23,

https://doi.org/10.1016/j.rcim.2019.02.003. 


\title{
Augmented Reality in Support of Industry 4.0 - Implementation Challenges and Success Factors
}

\author{
Tariq Masood ${ }^{1,2^{*}}$ and Johannes Egger ${ }^{1}$ \\ ${ }^{1}$ Institute for Manufacturing, Department of Engineering, University of Cambridge, 17 Charles Babbage Road, Cambridge \\ CB3 OFS, UK \\ ${ }^{2}$ Engineering Design Centre, Department of Engineering, University of Cambridge, Trumpington Street, Cambridge, CB2 1PZ, \\ UK \\ *E: tm487@cam.ac.uk
}

\begin{abstract}
Industrial augmented reality (AR) is an integral part of Industry 4.0 concepts, as it enables workers to access digital information and overlay that information with the physical world. While not being broadly adopted in some applications, the compound annual growth rate of the industrial AR market is projected to grow rapidly. Hence, it is important to understand the issues arising from implementation of AR in industry. This study identifies critical success factors and challenges for industrial AR implementation projects, based on an industry survey. The broadly used technology, organisation, environment (TOE) framework is used as a theoretical basis for the quantitative part of the questionnaire. A complementary qualitative part is used to underpin and extend the findings. It is found that, while technological aspects are of importance, organisational issues are more relevant for industry, which has not been reflected to the same extent in literature.
\end{abstract}

\section{Keywords}

Augmented Reality, Manufacturing, Technology, Organisation, Environment, TOE, Challenges, Critical Success Factors, Technology, Visualisation, Industry 4.0, Industrial Digitalisation, Cyber-Physical Systems, Internet of Things, IoT, Smart Factory, Survey

\section{Introduction}

Augmented reality (AR) is a key technology for enabling industry 4.0 concepts [1]. It is one of the main technologies to drive the development of such concepts in the industry according to the European Union [1]. AR enables employees to bridge the gap between the physical world and the increasingly important digital environment. Currently, the compound annual growth rate of the industrial AR market is projected to be around 74\% [2] between 2018 and 2025. The aggregated market of industrial AR is projected to reach $\$ 76$ billion in 2025 [2]. This significant growth is likely to be sustained or accelerated by the growing maturity of AR technology and the broad variety of applications within the industry. While the general importance of $A R$ is widely recognised, recent research has shown that the implementation for industrial applications is challenging [3].

Laboratory experiments, in general, indicate that AR supported tasks are more efficient in terms of task completion time and error rates [4-7]. However, it has been found that the increase in performance through AR depends on the complexity and nature of the task $[5,8]$. Thus, the selection of a suitable task is crucial. In addition, field experiments have uncovered that the performance of the AR system varied based on the experience of the workers: lower for expert workers while higher for untrained workers [9]. The effects on expert workers and novices were found to be significant.

In order to determine which issues are indeed of concern within the industry, a scientific approach to determine factors influencing the implementation success of AR systems is necessary. Thus, the effects of AR systems in experiments or through studies on other technologies uncovered factors on the dependent variable (i.e. implementation success), which can be explained and grounded in scientific theory. The framework chosen to be the basis of this research project is the technology, organisation, and environment (TOE) model [10]. One part of this study is a quantitative questionnaire, which aims to explain the relationship between the variables in question [11]. Despite the fact that the TOE framework is mainly used for information technology (IT) software systems, it is, in general, a framework explaining the adoption and implementation of innovation [10]. Thus, it is also suitable for innovations that include software and new hardware and user interface components, like AR.

In addition to the quantitative part, the questionnaire also contains a qualitative part. Here, the aim is to uncover success factors and challenges that have not been considered in recent experiments or in other technology implementation studies. Hence, the qualitative part complements the quantitative part by filling gaps and giving participants more freedom in drafting their answer [11].

Based on the facts presented, results of this study have a potential to increase the understanding of AR deployment within the industry. This paper also adds to the existing knowledge by providing new insights into critical factors that influence the 
success of AR implementation in industry. The following question is the basis of this research: 'Which factors influence the implementation success of industrial augmented reality?'.

This paper is composed of seven sections. Section 2 describes the background of AR in industry and technology adoption and implementation frameworks. Section 3 outlines the research model and the hypothesis to be tested by the quantitative part of the study. Then, section 4 explains the research methodology. In section 5, the data is analysed, and the results are presented from the qualitative part as well as the quantitative part. These results are discussed in section 6 . In the end, section 7 concludes this paper.

\section{Background}

This section briefly describes AR and its possible applications in industry. Then, the main theoretical basis for the research model is introduced. The section concludes with a brief review of research already conducted with the TOE and concerning AR adoption, implementation, and acceptance.

\subsection{Industrial Augmented Reality in support of Industry 4.0}

$A R$ is an important technology for the Industry 4.0 approach [2]. As those approaches promote a human-centric industrial environment, AR is one approach to augment the worker [12]. This technology enables humans to access the digital world through a layer of information positioned on top of the physical world. According to the Mixed Reality (MR) framework [13], $A R$ is positioned in between the physical and the virtual reality (VR). AR augments the real world without replacing it. This contrasts the concept of $V R$, where all the information is presented virtually.

Within different industries, the range of applications is broad. AR can be used for design and manufacturing applications [14], assembly operations, either in training $[6,15]$ or as an online guidance system for operators $[9,16,17]$. In logistic, 'pick-byvision' is a prominent concept utilising AR to indicate picking locations and quantities [18-23]. Other areas where AR can also be used include warehouse operations [24]. Another prominent field of applications includes quality assurance [25-27], maintenance [28-33], supervisory control and data acquisition (SCADA) tasks [34], through-life engineering services [35] and visualisation of instructions [36]. Implementation of AR technologies in human robot collaboration has also been a large trend of the recent years, e.g. safety enhancement [37] and automotive case study [38]. In short, as soon as operators depend on (real-time) information, AR can be used to intuitively display this information on site, which immerses the operator into the digital world of Industry 4.0 solutions.

AR applications include maintenance processes [39], where as soon as operators depend on or can profit from (real-time) information, AR can be used to intuitively display this information on site. A methodology was proposed to support technical writers in the creation of technical documentation e.g. manuals that could be used for AR interfaces [40]. Gattullo et al. [40] claimed that their proposed methodology choices are aligned with six design principles of Industry 4.0: interoperability, virtualization, decentralization, real-time capability, service orientation and modularity. Yew et al. [41] proposed a griddable distributed manufacturing system utilising AR interfaces as an intuitive online way to interact with a Cyber Physical Production System (CPPS). Their solution not only showed process information, but allowed for interaction with a milling machine directly, replacing computer and paper-based tasks. The physical objects within their CPPS are claimed to be completely replaceable with digital objects through AR. Other studies include: prototyping proactive and adaptive techniques for humanrobot collaboration in manufacturing using virtual reality while also providing a comparison of using AR vs virtual reality [42]. Interaction of real-virtual components has also been presented to facilitate assembly simulation and planning [43]. Other applications of AR include: interactive robot trajectory planning and simulation [44], and planning collision-free paths in robot programming [45].

The basic components of an AR system are the visualisation technology, a camera, a tracking system, and the user interface. Four main visualisation technologies are available for AR systems, namely head-mounted displays (HMDs), handheld devices (HHDs), static screens, and projectors. Depending on the task, the visualisation can either be stationary or has to be mobile. Especially for assembly applications, static screens or projectors can be used. Projection-based solutions utilise common projectors to display information directly onto the workspace $[8,9]$. Static screens can be used to display, e.g. interactive standard operating procedures (SOPs) [46] for the current status of the assembly and animate the next assembly step. Yet, HMDs are a focus of academia and industry. They enable operators to move around and access and read information handsfree, possibly speeding up operations significantly [47].

The AR tracking system enables digital objects to be placed accurately within the physical world. The most prominent AR technology is marker-based [3]. Physical markers are attached at certain places. These AR markers are then used to triangulate the correct position for a digital object. This technology is well understood and mature but has its drawbacks concerning reliability in industrial environments. Dust and dirt can decrease the readability. Hence, marker-less systems are being developed and already used, through which the physical environment is spatially mapped [48, 49]. The camera is the main sensor of an AR system to relate digital content to the physical world. Especially for marker-less solutions, several (stereoscopic) cameras are used to map the environment. For example, such a system is used by the Microsoft HoloLens.

The AR user Interface enables two-way communication from the system towards the user, but also feedback from the user. The main part is the visualisation system relaying information towards the user. Other technologies, like force feedback [50], 
or acoustic cues [51] are used as well. Concerning user input, prominent interaction methods are gesture recognition [52, 53], the direction of gaze [54], speech recognition [50], or discrete hardware solutions. Discrete user input hardware can range from mouse and keyboard to hand-scanners [55].

\subsection{Challenges around AR Implementation}

While not having gained a substantial foothold on a consumer level compared to VR [56], AR in support of Industry 4.0 is already being used and implemented. By providing flexible real-time information and the possibility of obtaining that information hands-free AR offers a substantial efficiency benefit for industrial applications [22, 57]. Additionally, AR promises to decrease the number of errors made [53], like picking or assembly errors and it provides an easy way to communicate with experts in maintenance tasks [58].

However, existing literature has reported on a variety of challenges in implementing AR solutions in the industry. Table 1 presents reported AR implementation experiments, their results and the challenges encountered during the projects. This selection focuses on experiments conducted in the field or those which utilised experienced industry operators. Major reported challenges include hardware and software issues, weight, ergonomics issues, limited user acceptance, visual fatigue and concentration performance issues, data transfer, integration and security issues, content authoring, adaptive instructions, marker tracking reliability and cost. That kind of studies uncovered that the complex industrial environment causes new challenges compared to laboratory environments [3]. 
Table 1 Challenges uncovered in field studies using AR systems (continued on the next page) (based on [3])

\begin{tabular}{|c|c|c|c|c|c|c|c|}
\hline Author & Year & Application & Technology & Sample & Dependent variables & Results & Challenges \\
\hline $\begin{array}{l}\text { Real et al. } \\
\text { [59] }\end{array}$ & 2011 & Inventorying & $\begin{array}{c}\text { HMD } \\
\text { Marker tracking }\end{array}$ & $\begin{array}{l}2 \text { IT specialists } \\
2 \text { workers }\end{array}$ & $\begin{array}{l}\text { Decoding time } \\
\text { Decoding distance } \\
\text { User experience }\end{array}$ & $\begin{array}{l}\text { Low user acceptance due to the weight of the } \\
\text { system (laptop and HMD was necessary due to } \\
\text { lack of in-built processing power of the HMD) } \\
\text { Decoding time and distance of QR codes was not } \\
\text { sufficient for the task }\end{array}$ & $\begin{array}{l}\text { Weight and ergonomics } \\
\text { Software decoding } \\
\text { capabilities } \\
\text { User acceptance can be } \\
\text { limited due to disruption of } \\
\text { existing processes }\end{array}$ \\
\hline $\begin{array}{l}\text { Serván et al. } \\
\text { [60] }\end{array}$ & 2012 & Assembly & $\begin{array}{c}\text { HHD } \\
\text { Marker tracking }\end{array}$ & Not disclosed & Task completion time & $\begin{array}{l}\text { Authoring and content maintenance time } \\
\text { decreased by } 90 \% \text {. } \\
\text { Assembly time decreased by } 50 \% \text {. } \\
\text { Working conditions and error rate reported } \\
\text { being improved (qualitative and subjective). }\end{array}$ & $\begin{array}{l}\text { Need for data integration } \\
\text { with product lifecycle } \\
\text { management (PLM) suites } \\
\text { Advances in AR devices and } \\
\text { tracking systems necessary }\end{array}$ \\
\hline $\begin{array}{l}\text { Porcelli et al. } \\
\text { [61] }\end{array}$ & 2013 & Maintenance & HMD & $\begin{array}{l}1 \text { remote expert } \\
2 \text { field technicians }\end{array}$ & $\begin{array}{l}\text { User experience } \\
\text { (Interviews) }\end{array}$ & $\begin{array}{l}\text { Increased need for expert guidance and } \\
\text { collaboration in maintenance tasks can be } \\
\text { supported by AR systems. }\end{array}$ & $\begin{array}{l}\text { Weight and ergonomics } \\
\text { Data transfer in remote } \\
\text { areas } \\
\text { Automate content } \\
\text { authoring } \\
\text { Change of training focus } \\
\text { and necessity }\end{array}$ \\
\hline $\begin{array}{l}\text { Gavish et al. } \\
\text { [62] }\end{array}$ & 2013 & Assembly & $\begin{array}{l}\text { HHD } \\
\text { Marker tracking } \\
\text { VR }\end{array}$ & $\begin{array}{l}40 \text { expert } \\
\text { technicians }\end{array}$ & $\begin{array}{l}\text { Task completion time } \\
\text { Error rate } \\
\text { Training time } \\
\text { Usability ( } 9 \text { Likert-scale } \\
\text { questions) }\end{array}$ & $\begin{array}{l}\text { Increased training time with } A R \text { and VR systems. } \\
\text { Decreased error rate after training with the AR } \\
\text { system. } \\
\text { Improved cognitive understanding of the tasks } \\
\text { through AR and VR. } \\
\text { AR is favoured compared to VR by the } \\
\text { technicians in terms of of usability. }\end{array}$ & $\begin{array}{l}\text { Cost } \\
\text { Long training time due to } \\
\text { unfamiliarity with AR and } \\
\text { VR systems } \\
\text { No clear performance } \\
\text { difference between AR and } \\
\text { VR }\end{array}$ \\
\hline $\begin{array}{l}\text { Hahn et al. } \\
{[6]}\end{array}$ & 2016 & Assembly & $\begin{array}{l}\text { HMD } \\
\text { Marker tracking }\end{array}$ & 30 workers & $\begin{array}{l}\text { Error rate } \\
\text { User experience }\end{array}$ & $\begin{array}{l}\text { The error rate of } 0 \text {. } \\
\text { High acceptance among participants. }\end{array}$ & $\begin{array}{l}\text { User interface visibility } \\
\text { Content for user interface } \\
\text { Marker tracking reliability }\end{array}$ \\
\hline $\begin{array}{l}\text { Syberfeldt et al. } \\
\text { [47] }\end{array}$ & 2016 & Assembly & $\begin{array}{c}\text { HMD } \\
\text { HHD } \\
\text { Projection } \\
\text { Marker tracking }\end{array}$ & $\begin{array}{l}7 \text { Swedish } \\
\text { manufacturing } \\
\text { companies }\end{array}$ & $\begin{array}{l}\text { Usability (Interviews } \\
\text { and Workshops) }\end{array}$ & $\begin{array}{l}\text { Perceived efficiency improvement. } \\
\text { The weight of HMDs is high. } \\
\text { HMDs are preferred over tablets as both hands } \\
\text { are free. }\end{array}$ & $\begin{array}{l}\text { Level of complexity impacts } \\
\text { efficiency gain through AR } \\
\text { Adaptive instructions } \\
\text { dynamically to improve } \\
\text { user acceptance } \\
\text { Data security and privacy } \\
\text { policies to increase user } \\
\text { acceptance }\end{array}$ \\
\hline
\end{tabular}




\begin{tabular}{|c|c|c|c|c|c|c|c|}
\hline $\begin{array}{l}\text { Stoltz et al. } \\
\text { [24] }\end{array}$ & 2017 & $\begin{array}{l}\text { Warehouse } \\
\text { operations }\end{array}$ & $\begin{array}{c}\text { HMD } \\
\text { HHD } \\
\text { Marker tracking }\end{array}$ & $\begin{array}{c}19 \text { non-expert } \\
\text { operators in } \\
\text { laboratory } \\
\text { experiment } \\
5 \text { expert operators } \\
\text { in field experiment }\end{array}$ & $\begin{array}{l}\text { Task completion time } \\
\text { Error rate (qualitatively) } \\
\text { Ease of use }\end{array}$ & $\begin{array}{l}\text { User preference towards AR application due to } \\
\text { high ease of use. } \\
\text { AR application was slower due to processing } \\
\text { power of HMD system used. } \\
\text { Decreased error rate can justify slower speed } \\
\text { through decreased re-work effort. }\end{array}$ & $\begin{array}{l}\text { Hardware limitations } \\
\text { Software limitations } \\
\text { User acceptance } \\
\text { Cost }\end{array}$ \\
\hline $\begin{array}{l}\text { Mourtzis et al. } \\
\text { [30] }\end{array}$ & 2017 & Maintenance & $\begin{array}{c}\text { HMD } \\
\text { HHD } \\
\text { Marker tracking }\end{array}$ & Not disclosed & $\begin{array}{l}\text { Task completion time } \\
\text { Cost }\end{array}$ & $\begin{array}{l}\text { No need of dispatching a technician to the site } \\
\text { where the robot is installed. } \\
\text { Cost reduction by nearly } 20 \% \text {. } \\
\text { Time reduction from } 9 \mathrm{~h} \text { to } 2 \mathrm{~h} \text {. }\end{array}$ & $\begin{array}{l}\text { Interoperability with } \\
\text { existing systems. } \\
\text { Automate content } \\
\text { authoring. }\end{array}$ \\
\hline $\begin{array}{l}\text { Doshi et al. } \\
\text { [63] }\end{array}$ & 2017 & Welding & Projection & $\begin{array}{l}1 \text { inexperienced } \\
\text { worker (off-line) } \\
4 \text { shifts with } 8 \\
\text { experienced } \\
\text { workers (in-line) }\end{array}$ & Welding accuracy & $\begin{array}{l}\text { Significantly smaller error distribution of the spot } \\
\text { weld position. } \\
15 \% \text { to } 52 \% \text { improvements depending on the } \\
\text { position of the weld. }\end{array}$ & $\begin{array}{l}\text { Effect of visual cues on } \\
\text { accuracy }\end{array}$ \\
\hline $\begin{array}{l}\text { Funk et al. } \\
\text { [9] }\end{array}$ & 2017 & Assembly & Projection & $\begin{array}{l}3 \text { expert workers } \\
3 \text { untrained } \\
\text { workers } \\
\text { (all employees of a } \\
\text { car manufacturing } \\
\text { company) }\end{array}$ & $\begin{array}{l}\text { Task completion time } \\
\text { Error rate } \\
\text { TASA-TLX } \\
\text { User experience } \\
\text { (Interviews) }\end{array}$ & $\begin{array}{l}\text { Expert workers: } \\
\text { Significantly higher task completion time due to } \\
\text { distraction by projection according to interviews. } \\
\text { No indication of higher cognitive task load } \\
\text { measured by NASA-TLX compared to } \\
\text { conventional setting. } \\
\text { Novice workers: } \\
\text { Improved learning curve. Lower NASA-TLX } \\
\text { compared to expert workers. } \\
\text { Distraction by AR system after a while according } \\
\text { to interviews. }\end{array}$ & $\begin{array}{l}\text { AR slows workers down } \\
\text { due to distractions } \\
\text { Adaptive instructions based } \\
\text { on the workers experience } \\
\text { Diminishing reward curve } \\
\text { for using AR in assembly } \\
\text { training }\end{array}$ \\
\hline $\begin{array}{l}\text { Murauer et al. } \\
\text { [55] }\end{array}$ & 2018 & Picking & $\begin{array}{c}\text { HMD } \\
\text { Marker tracking }\end{array}$ & $\begin{array}{l}5 \text { production } \\
\text { workers }\end{array}$ & $\begin{array}{l}\text { Task completion time } \\
\text { Error rate } \\
\text { NASA-TLX } \\
\text { Visual fatigue } \\
\text { questionnaire } \\
\text { d2 test of attention } \\
\text { Usability (system } \\
\text { usability scale) }\end{array}$ & $\begin{array}{l}\text { AR decreases error rate. } \\
\text { Utilising a scan glove improves task completion } \\
\text { time. Depending on the supporting scanning } \\
\text { equipment, however, the task completion time } \\
\text { can increase. } \\
\text { AR can increase the cognitive workload, } \\
\text { depending on the scanner system. }\end{array}$ & $\begin{array}{l}\text { Visual fatigue and } \\
\text { concentration performance } \\
\text { levels. }\end{array}$ \\
\hline
\end{tabular}




\subsection{Technology Adoption and Implementation Models}

Introduced by [10], the TOE framework covers one segment of the book 'The Process of Technological Innovation' [64]. It originally covered the adoption and implementation of technologies and how the context of a firm influences that process. More recently, it has also been adapted and used for implementation and post-adoption issues [65-67]. Due to its broad use, the TOE has an empirical basis across different industries, like healthcare [68], retail [69], or manufacturing [70], and technologies, e.g. radio frequency identification (RFID) [71], cloud computing [72], or enterprise resource planning (ERP) systems [66, 73]. It has also been proposed to be used for explaining the AR adoption in e-commerce [74]. Table 2 lists studies utilising the TOE framework for Industry 4.0 related technologies and the constructs used.

Table 2 Review of TOE framework studies for Industry 4.0 relevant technologies and the used constructs

\begin{tabular}{|c|c|c|c|c|}
\hline Author & Year & Innovation & Constructs & \\
\hline \multirow{3}{*}{$\begin{array}{l}\text { Arnold et } \\
\text { al. } \\
{[76]}\end{array}$} & \multirow[t]{3}{*}{2018} & \multirow{3}{*}{$\begin{array}{l}\text { Industry } 4.0 \text { in } \\
\text { general }\end{array}$} & Technology: & Relative advantage, Perceived challenges, Compatibility \\
\hline & & & Organisation: & Firm size, Top management support, Absorptive capacity \\
\hline & & & Environment: & $\begin{array}{l}\text { Competition, Environmental uncertainty, Perceived } \\
\text { outside support }\end{array}$ \\
\hline \multirow[t]{3}{*}{$\begin{array}{l}\text { Yeh et al. } \\
{[78]}\end{array}$} & \multirow[t]{3}{*}{2018} & \multirow[t]{3}{*}{$\begin{array}{l}\text { 3D Printing } \\
\text { (qualitative study) }\end{array}$} & Technology: & $\begin{array}{l}\text { Technology infrastructure, Technology integration, } \\
\text { Relative advantage }\end{array}$ \\
\hline & & & Organisation: & $\begin{array}{l}\text { Organisational readiness, Top management support, } \\
\text { Managerial obstacles }\end{array}$ \\
\hline & & & Environment: & $\begin{array}{l}\text { Competitive pressure, Expectations of market trends, } \\
\text { Trading partner, Government policy }\end{array}$ \\
\hline \multirow{3}{*}{$\begin{array}{l}\text { Jia et al. } \\
\text { [67] }\end{array}$} & \multirow[t]{3}{*}{2017} & \multirow{3}{*}{$\begin{array}{l}\text { Enterprise Web } \\
2.0\end{array}$} & Technology: & Perceived usefulness \\
\hline & & & Organisation: & Firm scope, Firm size, Subjective norms \\
\hline & & & Environment: & Competitive pressure \\
\hline \multirow{3}{*}{$\begin{array}{l}\text { Kumar et } \\
\text { al. } \\
{[74]}\end{array}$} & \multirow[t]{3}{*}{2016} & \multirow{3}{*}{$\begin{array}{l}\text { AR in e- } \\
\text { commerce }\end{array}$} & Technology: & Technology competence, Relative advantage \\
\hline & & & Organisation: & $\begin{array}{l}\text { Decision makers knowledge, Financial strength, Top } \\
\text { management support }\end{array}$ \\
\hline & & & Environment: & Consumer readiness, Competitive pressure \\
\hline \multirow{3}{*}{$\begin{array}{l}\text { Sun et al. } \\
{[77]}\end{array}$} & \multirow[t]{3}{*}{2016} & \multirow{3}{*}{$\begin{array}{l}\text { Big Data } \\
\text { (qualitative study) }\end{array}$} & Technology: & Relative advantage, Complexity, Compatibility, Cost, ... \\
\hline & & & Organisation: & $\begin{array}{l}\text { Technology readiness, Appropriateness, Management } \\
\text { support, ... }\end{array}$ \\
\hline & & & Environment: & $\begin{array}{l}\text { Regulatory environment, Institutional based trust, Trading } \\
\text { partner readiness, ... }\end{array}$ \\
\hline \multirow{3}{*}{$\begin{array}{l}\text { Wei et al. } \\
{[82]}\end{array}$} & \multirow[t]{3}{*}{2015} & \multirow[t]{3}{*}{ RFID } & Technology: & Relative advantage, Complexity \\
\hline & & & Organisation: & $\begin{array}{l}\text { IT infrastructure, Managerial capability, Absorptive } \\
\text { capacity }\end{array}$ \\
\hline & & & Environment: & $\begin{array}{l}\text { Competition intensity, Regulatory support, Environmental } \\
\text { uncertainty }\end{array}$ \\
\hline \multirow{3}{*}{$\begin{array}{l}\text { Oliveira et } \\
\text { al. } \\
{[84]}\end{array}$} & \multirow[t]{3}{*}{2014} & \multirow[t]{3}{*}{ Could computing } & Technology: & Technology readiness \\
\hline & & & Organisation: & Top management support, Firm size \\
\hline & & & Environment: & Competitive pressure, Regulatory support \\
\hline \multirow{3}{*}{$\begin{array}{l}\text { Wang et } \\
\text { al. } \\
\text { [71] }\end{array}$} & \multirow[t]{3}{*}{2010} & \multirow[t]{3}{*}{ RFID } & Technology: & Relative advantage, Complexity, Compatibility \\
\hline & & & Organisation: & $\begin{array}{l}\text { Top management support, Firm size, Technology } \\
\text { competence }\end{array}$ \\
\hline & & & Environment: & $\begin{array}{l}\text { Competitive pressure, Trading partner pressure, } \\
\text { Information intensity }\end{array}$ \\
\hline
\end{tabular}

Compared to another prominent technology adoption and implementation framework, the diffusion of innovation (DOI) theory [75], the TOE also includes the environmental context. While the technological and the organisational context are coherent in the TOE and DOI framework, various studies have shown that the environmental construct can be the source of barriers and drivers [77]. For example, technologies with high costs or significant organisational changes require support from the external environment to be implemented successfully $[66,71]$. The knowledge of AR within firms is often not fully developed. External support and knowledge can help to gain an understanding of the technology, its possibilities and drawbacks. Hence, the TOE framework was chosen compared to the DOI. 
Other technology adoption models are more focused on a certain aspect. The technology adoption model (TAM) [79, 80], the unified theory of acceptance and use of technology (UTAUT) [81], and the theory of planned behaviour (TPB) [83] focus on the individual user. This is highly appropriate for end-user applications [85]. The TAM has already been proposed to investigate the AR acceptance for tourism applications [86]. A study by [87] also utilises the TAM theory in the context of AR in the online fashion retail industry. Yet, for companies introducing AR for their operations, this view is too limited. New technologies can induce organisational changes with significant impact. Those considerations are not part of the theories aforementioned.

The TOE consists of three elements which affect the adoption and implementation, namely the technological context, the organizational context, and the environmental context (see Fig 1). Behind each of the constructs are different measures, which can promote or impede the desired outcome. These variables depend on the industry and the technology [88]. Over its existence, the TOE framework has been advanced continuously to extend its applicability to different industries and technologies, like additive manufacturing [78], big data [77], or Industry 4.0 [76] ensuring its continued validity. More recently, new constructs have been added as well [78] and advances made to integrate the TOE with other models [89].

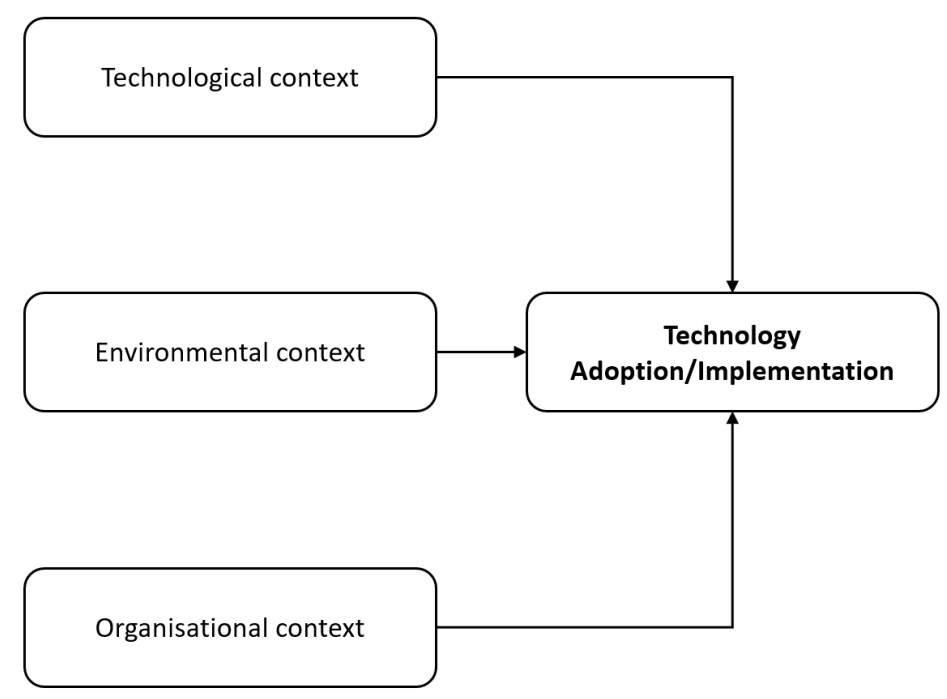

Fig 1 TOE framework (based on [10])

The technological context sets the frame for the technology available in the firm and the technology the research focuses on. It includes the characteristics of the technology, the compatibility and interoperability with the current system. Depending on the research question (Which factors influence the implementation success of industrial augmented reality?), it may also incorporate substitutes for the technology in question [72] or focus on technologies that are already in place [82] within the company as those factors can influence the technology adoption [10]. Another important factor can be the technological readiness or maturity.

The organisational context relates to the characteristics and resources of the firm itself. The support of new technologies and the readiness to implement them are measured within this construct [10]. In addition, the resources available [90] - often related to the size of a company [91] -and the supportiveness of the company culture towards the new technology have been shown to influence the success of technology implementation [92]. The (top) management support was found to play a role in promoting innovation [78].

The environmental context extends the model to external players [10]. Companies never operate isolated but move into an ecosystem of their industry, competitors, regulations, standards, etc. When working with new technologies, the knowledge about that technology within the company is inherently low. External support and synergy effects e.g. within an industry can provide knowledge assets supporting the technology implementation [93]. On the other hand, external factors could constrain the implementation (e.g. regulations).

$A R$ is a complex technology. This complexity arises on the one hand from the technology itself. The system has to be integrated into the current IT infrastructure [94]. Pre-existing content needs to be adapted to the technology, which often requires a deep understanding of the technology $[33,95]$. In addition, the hardware, especially HMDs, were previously not common in industrial environments. The challenges arising from the ergonomic effects of the weight, the user interface, and the information design and content are new to the industry [28].

On the other hand, it causes substantial organisational changes. This can relate to the processes supported by AR itself, the organisational structure and employee education [61], or the user acceptance [96]. The latter one is likely caused by the 
unfamiliarity with such a system. While computers and the interaction with them have been around in an enterprise environment for years, AR is a new technology.

To sum up, previous studies have uncovered a number of possible issues that AR implementation faces. Yet, they have not been explored in an aggregated way yet. As those challenges cover technological, organisational, and environmental issues, the TOE framework provides a suitable lens to investigate which factors influence the technology implementation.

\section{Research Model and Hypotheses Development}

The research model and the hypotheses are discussed in this section. The research model is presented in Fig 2 . The dependent variable, the implementation success, is on the right side. The independent constructs based on several measures (also see Appendix A for measures) are on the left side and classified according to the TOE framework. The constructs and the variables are mainly based on the previous TOE and AR research.

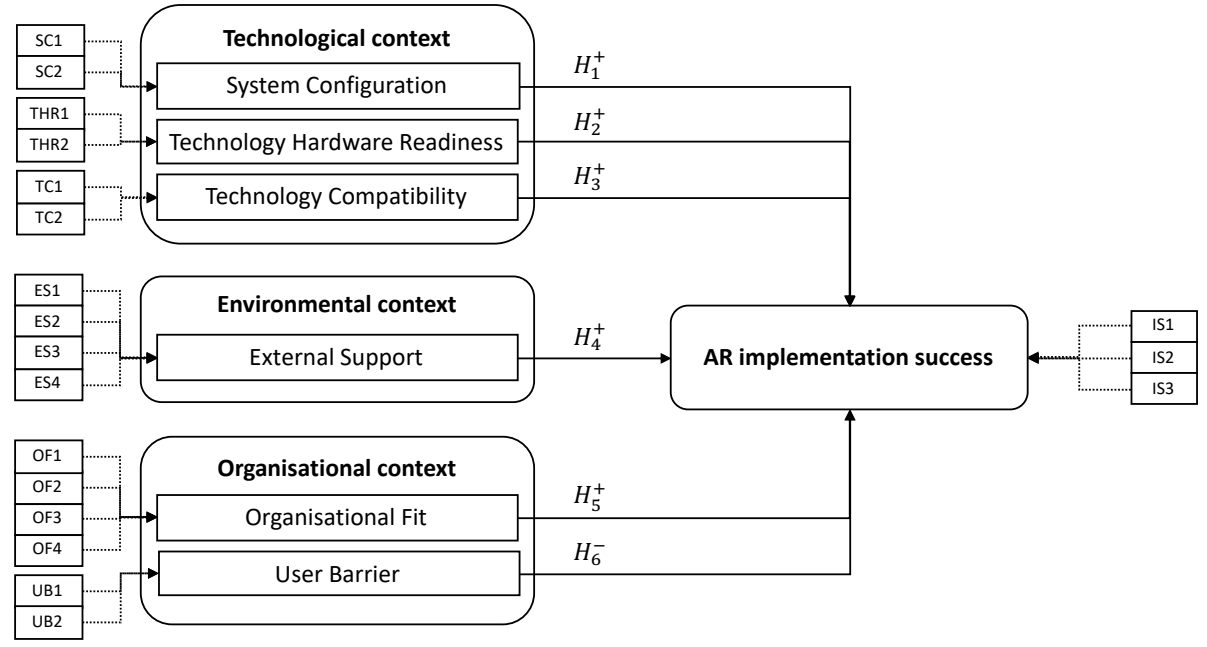

Fig 2 Research model and hypothesis based on the TOE framework

The implementation success (IS) is to some extent quantifiable in terms of efficiency improvement. A variety of studies focus their experiments on improving the performance (for example, task completion time) when supporting a worker through AR $[97,98]$. This study, however, defines implementation success by the willingness of the company to increase the usage of $A R$ in terms of application and location. Additionally, the organisation needs to gain a substantial benefit from the AR system. Those measures make up the construct of the dependent variable.

\subsection{Technology Context}

3.1.1 System Configuration (SC)

For software systems, the system architecture configuration and integration is substantial for obtaining the benefits as soon as possible after the implementation [66]. It is necessary to test the system before deploying it finally and working out bugs and other possible causes of breakdowns. Despite the fact that it is impossible to fully test the system and implement it without any possibility of failure during standard operation, a thorough testing regime can decrease the chance of that happening.

Another important factor that expands this aspect when using AR compared to pure software systems is the hardware. The AR hardware configuration, especially the visualisation technology, has a significant impact on the overall system performance [16]. Even when the decision is made to use HMDs, the difference in performance between different devices is substantial [23]. Pilot studies are necessary on the one hand, to determine how to configure the software system. On the other hand, different devices can be tested during pilot studies by the potential end-users of the system. A vast variety of products is already commercially available, all having their individual benefits and drawbacks. Similar to the vast number of ERP solutions, pilot studies are part of a sound system configuration $[99,100]$. This can improve the system configuration and increase the possibility of implementation success in the end. Hence, the following hypothesis is proposed.

Hypothesis 1: The system configuration is positively associated with the implementation success of AR systems.

3.1.2 Technology Hardware Readiness (THR)

While AR is already successfully used in some applications, it is not ready yet for industrial deployment in others. The technology needs to be mature enough to support a certain business case. Compared to software systems, where the current readiness of the IT system available is often key [91, 93], for AR, the readiness of the hardware seems to be a critical factor according to studies based on industrial work $[9,47,101]$. Hence, this construct is based on the technology constructs used previously but focuses on the hardware perspective to determine if the capabilities available support a certain task. 
The construct of the technology readiness is based on the capability of the technology. Especially the information visualisation and the capability of being used by a worker for a whole day impact the readiness of the AR system to successfully support the task in question. The following hypothesis is posed.

Hypothesis 2: The technology readiness is positively associated with the implementation success of AR systems.

\subsubsection{Technology Compatibility (TC)}

If a technology is perceived as coherent with the current practices, values, or needs it is compatible [71]. This can relate to a variety of different items, like the existing IT system, or current processes within the firm. Similar to the system configuration construct, it is important for AR systems to also consider the effects of the hardware used in current practice. It has been shown that AR hardware can cause perceived issues with the current safety system regarding operator awareness [28]. Other studies have confirmed that compatibility is a facilitator for technology adoption and implementation [84]. Thus, the following hypothesis is proposed.

Hypothesis 3: The technology compatibility is positively associated with the implementation success of AR systems.

\subsection{Environmental Context: External Support (ES)}

AR is a complex technology and inherently in implementing a new technology, the knowledge about a new technology is low in the beginning. The implementation success of AR can be influenced by the external support. Different parties can be consulted before making an adoption decision or during the implementation process. However, in some studies, this assumption was not supported by the data obtained $[65,76]$.

The vendor of the system can provide information and know-how concerning AR before the adoption decision, but especially during the implementation phase. Additionally, industry associations or other companies in the same or other sectors utilising AR can be consulted. Industry associations often provide access to information for their members concerning new technologies like AR [102].

Industrial standards from external entities decrease the uncertainty for individual firms, as a whole industry operates under those standards. Even when not published yet, standardisation organisations may have insights into the informal industrial standard. The IEEE standards association is active in standardising a wide variety of issues around AR, like environment safety, or user interface design [103].

External support from different sources can alleviate the challenges connected to a knowledge gap concerning a new technology. Hence, the following hypothesis is proposed.

Hypothesis 4: External support is positively associated with the implementation success of AR systems.

\subsection{Organisation Context}

3.3.1 Organisational Fit (OF)

The organisation needs to be prepared and ready before implementing AR. Especially two perspectives have been identified as relevant in AR and TOE literature, namely adapting the process $[61,104]$ and involving the users before and during the implementation process [62]. The processes AR supports need to be adapted and re-engineered to fit the technology. Using an AR technology might induce a change in how people within a company are trained for the process, or how information gets processed, distributed, or handled.

Before and during the implementation phase, users need to be involved and educated about the new technology they will be using. It is necessary to do so, as their daily routine will be disrupted by the implementation [64]. For example, when changing from a paper-based to AR supported assembly instructions, employees need to be trained on the technology to [9, 59]. This is different from the system configuration construct which deals with specific technical issues of the implementation. This construct deals with the how the organisation can support the implementation of AR.

To conclude, a holistic and thorough preparation and support are necessary to receive the potential benefits from AR. This leads to the following hypothesis.

Hypothesis 5: The organisational fit is positively associated with the implementation success of AR systems.

\subsubsection{User Barrier (UB)}

This construct is, compared to other constructs not entirely based on the TOE framework. It is based on the idea to enrich the TOE framework based on the technology user context as part of the organisation [105]. Its goal is to assess how potential issues concerning the user acceptance can affect the implementation, like ergonomic problems or the perceived trust of users in the technology. The user acceptance is often named as an integral part of successfully implementing technologies. This was also stated for AR [24, 101]. In some cases, novel hardware (for example HMDs) is used for the AR system additionally to the technology itself, which might further increase user barriers. For any innovation, the effects on users and their job (profile) are a central part of its implementation [64, 104]. 
Further developing the TOE through enriching including individual factors has been suggested $[88,105]$. This construct does not go as far as including factors on an individual level. Rather, the perceived effect it has on users of the technology and the perceived attitude of users towards the technology is captured. If the technology has negative effects (for example due to bad ergonomics) on the users, this is a barrier decreasing the likelihood of implementation. Additionally, if users mistrust the technology, it is not feasible to force a technology on them. As those factors hinder a successful implementation, the following hypothesis is proposed. This construct, based on the 'ease of use' TAM construct [79, 80, 106], has already been applied in a similar manner through the TOM framework [89].

Hypothesis 6: User barrier is negatively associated with the implementation success of AR systems.

The research model is based on the six hypotheses presented earlier, which can be tested through the following methodology.

\section{Research Methodology}

This section explains the research methodology of the quantitative and qualitative part of the survey. The implementation success of AR can only be determined through surveying participants in implementation or pilot projects for industrial AR applications. The quantitative part is the core of this study, as it relates to the TOE framework. The qualitative part deepens the understanding of current challenges and enables participants to point out challenges not yet uncovered by academia. The goal of this mixed methodology design is to complement the results from the quantitative questionnaire, which is more restrictive in terms of answers than the qualitative part [11]

\subsection{Sampling and sample frame}

The range of sample sizes from similar studies employing a technology adoption framework (TOE or DOI) is significant. In the review article from [107], the sample sizes range from 89 to more than 4000 . Two surveys very similar to this proposed research, but focusing on other technologies, have reported sample sizes of 65 [66] and 133 [71] respectively.

In order to validate the lower limit from similar studies, a sample size calculator was used [108]. By setting a confidence level of $95 \%$ and calculating the confidence interval with 84 participants (see section 4.2 ), the confidence interval is at 0.107 . It is necessary to mention that the sample size calculator is based on a simple random, thus probabilistic, sampling technique. However, it gives a good indication of the approximate size of the sample necessary and suggests the validity of sample sizes from other studies. Contrary to the assumptions of the approximate sample size calculated above, non-random sampling is used in this case, as the population, in the end, is not known. The two main sampling techniques used are purposive sampling and snowball sampling [11].

Currently, the compound annual growth rate of the industrial AR market is projected to be around 74\% [2] between 2018 and 2025. The aggregated market of industrial AR is projected to reach $\$ 76$ billion in 2025 [2]. This significant growth is likely to be sustained or accelerated by the growing maturity of AR technology and the broad variety of applications within the industry. An increasing number of companies will be faced with issues arising from AR implementation. Hence, the target population of this study are companies who implemented AR or conducted AR pilot studies for industrial applications. To be more specific, the questionnaire is targeted at people who have been involved with the aforementioned projects. Their expertise and first-hand experience can determine the influencing factors for AR implementation.

\subsection{Data collection}

A total of 365 individuals were selected as possible participants for the survey. The information necessary to identify those individuals was obtained through internet research utilising professional news homepages, professional social networks, (AR) industry alliances, and industry contacts. The main prerequisite to be eligible for participation was the direct involvement in AR implementation or pilot projects, e.g. as project lead. This criterion was again tested in the questionnaire to make sure it is fulfilled. A sustained use of AR after a pilot-project was not necessary, as also failed attempts provide insights into factors influencing the implementation success.

We targeted the prospective participants directly through e-mail or professional social networks. The messages contained a description of the project and contained an anonymous link leading to the online questionnaire. These messages were sent out in May, June, and July 2018. A report of the results provided in an anonymous link at the end of the questionnaire was provided as an incentive for participation. In total, 84 valid questionnaires were filled out, which corresponds with a response rate of $23 \%$.

\subsection{Quantitative Part}

In this section, the methodology of the quantitative part is pointed out. It focuses on the sampling procedure and the sample characteristics, the instrument development, and finally the data collection process itself.

For each construct, a set of measures was identified. The majority of the measures are based on previous research to ensure and maintain validity and adapted to fit the AR context. Appendix A: Measures shows all measures and, if applicable, their source in previous TOE research. In addition, the measures were based on previous research concerned with industrial $A R$, which identified likely challenges and influencing factors when implementing AR.

After obtaining feedback concerning the questionnaire from one AR expert and two experts in designing quantitative questionnaires concerning the design, applicability, and clarity of language, the questionnaire was adapted [11]. Through this 
feedback process and the strong linkage of the questionnaire to both, TOE and AR literature, the validity and applicability of the questionnaire can be substantiated. The partial least square method (PLS-SEM) was used to analyse the data.

Nearly all of the measures were sampled through a five-point likert scale, reaching from definitely true to definitely false. Two exceptions are concerned with the efficiency improvement obtained through AR. These metric scales, however, are compatible to ordinal scales.

\subsection{Qualitative Part}

The qualitative part of the survey aims at complementing the information obtained from the quantitative part by uncovering the distribution of current issues based on the TOE framework and determining if there are pressing industrial issues that are not in the focus on research yet. The two main set of questions are concerned with success factors and challenges when implementing industrial AR.

Concerning the success factors, participants were given a multiple-choice question of predefined and open success factors to choose as being the most important. Then, the ones selected had to be ranked based on their importance, where 1 is the most important success factor. The question concerning challenges was posed as an open question. It was posed before exposing participants to the pre-defined success-factors or the quantitative part of the questionnaire. Hence, the answers are not influenced by the choices presented later in the survey. 


\section{Analysis and Results}

Before analysing the quantitative and qualitative results in detail, a brief overview of the sample profile is given in Table 3.

Table 3 Sample profile. For the sector and the application, the number is higher than the number of answers, as multiple options could have been selected.

\begin{tabular}{|c|c|c|}
\hline & Count & Percentage \\
\hline \multicolumn{3}{|l|}{ Roles } \\
\hline Project Lead & 23 & $27.4 \%$ \\
\hline C-suite & 15 & $17.9 \%$ \\
\hline Manager (Development, Applications, Innovation) & 22 & $26.2 \%$ \\
\hline Consulting & 4 & $4.8 \%$ \\
\hline Other & 9 & $10.7 \%$ \\
\hline No answer & 11 & $13.1 \%$ \\
\hline Total & 84 & $100.0 \%$ \\
\hline \multicolumn{3}{|l|}{ Sector } \\
\hline Aerospace & 7 & $6.1 \%$ \\
\hline Automotive & 28 & $24.3 \%$ \\
\hline Chemical / Pharmaceutical & 6 & $5.2 \%$ \\
\hline Commerce & 4 & $3.5 \%$ \\
\hline Construction & 3 & $2.6 \%$ \\
\hline Energy & 7 & $6.1 \%$ \\
\hline Electronics & 7 & $6.1 \%$ \\
\hline FMCG & 2 & $1.7 \%$ \\
\hline Mining & 4 & $3.5 \%$ \\
\hline Transport & 8 & $7.0 \%$ \\
\hline AR Vendor / Provider & 30 & $26.1 \%$ \\
\hline Other & 9 & $7.8 \%$ \\
\hline Total & 115 & $100.0 \%$ \\
\hline \multicolumn{3}{|l|}{ Company Size } \\
\hline below 10 & 19 & $22.6 \%$ \\
\hline $11-250$ & 18 & $21.4 \%$ \\
\hline $251-1000$ & 4 & $4.8 \%$ \\
\hline $1001-10000$ & 10 & $11.9 \%$ \\
\hline above 10000 & 33 & $39.3 \%$ \\
\hline Total & 84 & $100.0 \%$ \\
\hline \multicolumn{3}{|l|}{ Application } \\
\hline Quality Assurance & 20 & $10.2 \%$ \\
\hline Maintenance & 32 & $16.2 \%$ \\
\hline Support & 28 & $14.2 \%$ \\
\hline Training & 33 & $16.8 \%$ \\
\hline Assembly & 27 & $13.7 \%$ \\
\hline Picking & 14 & $7.1 \%$ \\
\hline Navigation & 12 & $6.1 \%$ \\
\hline Design & 16 & $8.1 \%$ \\
\hline Other: & 15 & $7.6 \%$ \\
\hline Total & 197 & $100.0 \%$ \\
\hline
\end{tabular}

\subsection{Quantitative Results}

In this section, the statistical model is tested for validity and the partial least square regression method is used to analyse the statistical results due to its lower sensitivity to lower sample sizes [109]. The tools used to analyse the results include SPSS 25 and SmartPLS 3. Fig 3 shows the analysis done. First, the prerequisites to conduct a principal component analysis and a partial least square analysis are tested. Then those two tests are conducted. Afterwards, the validity and reliability of the model shown in Fig 2 are tested as well as possible multicollinearity between the constructs. 


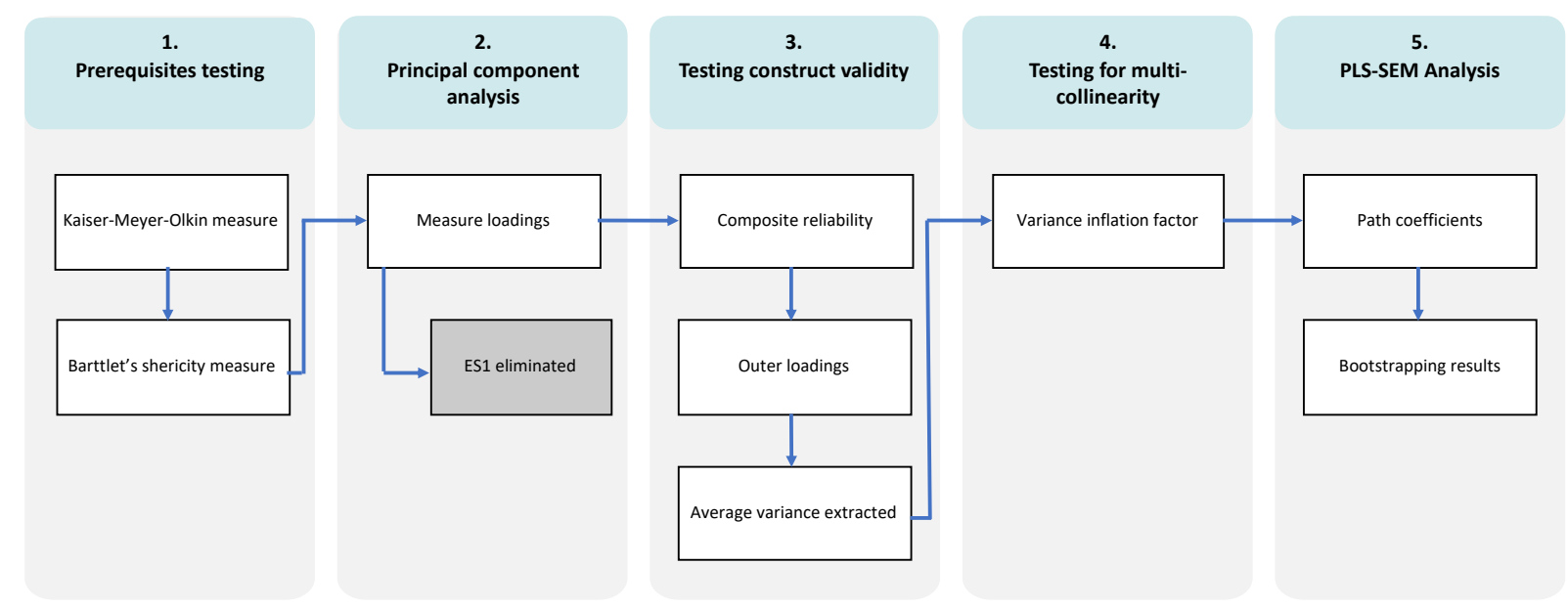

Fig 3 Validity, Reliability, and Analysis process of the quantitative data. The blue boxes show what was tested/done and the white boxes show the measures used to do so.

\subsubsection{Validity and Reliability}

To determine if the data, in general, can be accepted to conduct a principal component analysis (PCA), the Kaiser-MeyerOlkin (KMO) test can be conducted [110]. A factor analysis aggregates different measures for latent variables (factors) [110]. One cut-off threshold for the KMO test measure is 0.5 [110]. If the KMO test returns a value greater than 0.5 a factor analysis can be conducted, otherwise the sample size is too small. Additionally, Bartlett's test of sphericity tests the hypothesis that the correlation matrix of the measures is an identity matrix [110]. If the correlation matrix is the identity matrix, the measures don't correlate and, hence, cannot be aggregated in a factor analysis. Table 4 shows the results of the KMO test and the sphericity test. As the significance of the sphericity test is 0 , the hypothesis can be rejected. Additionally, the KMO measure is greater than 0.5 . Thus, a factor analysis can be conducted.

Table 4 Results of the KMO and sphericity test

\begin{tabular}{llr}
\hline Kaiser-Meyer-Olkin Measure & & 0.503 \\
\hline Bartlett's Test of Sphericity & Approx. Chi-Square & 302.455 \\
& Significance & 0.000 \\
\hline
\end{tabular}

The constructs based on the measures were validated through a confirmatory PCA. A PCA determines which measures can be represented the best by a latent variable. It showed that all of the measured load on the correct construct except for ES1, which was eliminated because of loading onto the intended and on another latent variable. Another PCA without ES1 showed that the constructs were stable. Table 5 shows the results with suppressing primary loading factors below 0.4 of the final PCA. 


\begin{tabular}{|c|c|c|c|c|c|c|c|}
\hline \multirow[b]{2}{*}{ Measures } & \multicolumn{7}{|c|}{ Latent Variable } \\
\hline & $\begin{array}{l}\text { Organisational } \\
\text { Fit (OF) }\end{array}$ & $\begin{array}{c}\text { Implementation } \\
\text { Success (IS) }\end{array}$ & $\begin{array}{c}\text { External } \\
\text { Support } \\
\text { (ES) }\end{array}$ & $\begin{array}{c}\text { Technology } \\
\text { Compatibility } \\
\text { (TC1) }\end{array}$ & $\begin{array}{l}\text { Technology } \\
\text { Hardware } \\
\text { Readiness (THR) }\end{array}$ & $\begin{array}{c}\text { System } \\
\text { Configuration } \\
\text { (SC) }\end{array}$ & $\begin{array}{c}\text { User } \\
\text { Barrier } \\
\text { (UB) }\end{array}$ \\
\hline OF1 & 0.795 & & & & & & \\
\hline OF2 & 0.732 & & & & & & \\
\hline OF3 & 0.687 & & & & & & \\
\hline OF4 & 0.557 & & & & & & \\
\hline IS1 & & 0.860 & & & & & \\
\hline IS2 & & 0.837 & & & & & \\
\hline IS3 & & 0.507 & & & & & \\
\hline ES2 & & & 0.843 & & & & \\
\hline ES3 & & & 0.623 & & & & \\
\hline ES4 & & & 0.500 & & & & \\
\hline TC1 & & & & 0.731 & & & \\
\hline TC2 & & & & 0.546 & & & \\
\hline THR1 & & & & & 0.863 & & \\
\hline THR2 & & & & & 0.448 & & \\
\hline $\mathrm{SC} 1$ & & & & & & 0.827 & \\
\hline SC2 & & & & & & 0.661 & \\
\hline UB1 & & & & & & & 0.740 \\
\hline UB2 & & & & & & & 0.648 \\
\hline
\end{tabular}

Table 6 shows the composite reliability as a metric for the internal consistency of the different constructs. The different constructs used have a composite reliability higher than 0.6 . A value from 0.6 to 0.7 is frequently used as a threshold level [109]. The average variance extracted (AVE) determines how well a latent variable explains its measures. A common threshold is 0.5 , which means that on average $50 \%$ of the variance of a measure explained through the latent variable [111]. In the proposed model, the latent variable External Support has an AVE below 0.5. Despite the fact that the external support does not pass the AVE greater than 0.5 requirements it is kept within the model as an AVE value between 0.4 and 0.5 is acceptable if the composite reliability is higher than 0.6 [112].

Table 6 Composite reliability, AVE, and VIF of the respective latent variables

\begin{tabular}{lccc}
\hline & Composite Reliability & AVE & VIF \\
\hline IS & 0.845 & 0.648 & \\
SC & 0.828 & 0.707 & 1.25 \\
UB & 0.744 & 0.601 & 1.131 \\
THR & 0.823 & 0.7 & 1.279 \\
TC & 0.772 & 0.63 & 1.398 \\
OF & 0.847 & 0.588 & 1.389 \\
ES & 0.644 & 0.427 & 1.225 \\
\hline
\end{tabular}

To determine the severity of multicollinearity between the latent variables, the variance inflation factor (VIF) or its tolerance, which is the reciprocal value of the VIF, are used. If the VIF is high, the risk increases that the latent variables are not independent. Different critical thresholds are suggested in the literature. Common thresholds in literature are 5 [109] or 10 [110]. Table 6 shows that multicollinearity is no issue. 


\subsubsection{Data analysis}

The PLS-SEM was used to analyse the data. PLS-SEM does not have 'identification issues with small sample sizes' [109] and does not assume certain distributions, like the normal distribution. In addition, it works with ordinal scales, like likert scales [109]. Hence, the analysis method is applicable to the dataset.

To analyse the dataset, the research model (see Fig 2) was modelled in SmartPLS 3. Then, the PLS-SEM algorithm was run, which determines the coefficients between the latent variable and the dependent variable. As PLS-SEM does not assume a normal distribution, another way to determine the significance of coefficients is necessary. The bootstrapping algorithm draws subsamples (bootstrap samples) from the population sampled and can determine measures of accuracy, like significance [109]. The different subsamples draw randomly with replacement from the sample. Hence, different observations can be multiple times within a bootstrap sample or not at all. Hence, the number of subsamples needs to be large. A number of 5000 is accepted in the literature [109]. Fig 4 shows the results from the PLS-SEM algorithm and the bootstrapping procedure (with 5000 subsamples). On the arrows from the latent variables to the dependent variable, the factors or path coefficients $(p c)$ are displayed. The superscript after each number indicates the significance. Next, to the dependent variable, the $R^{2}$ score is shown.

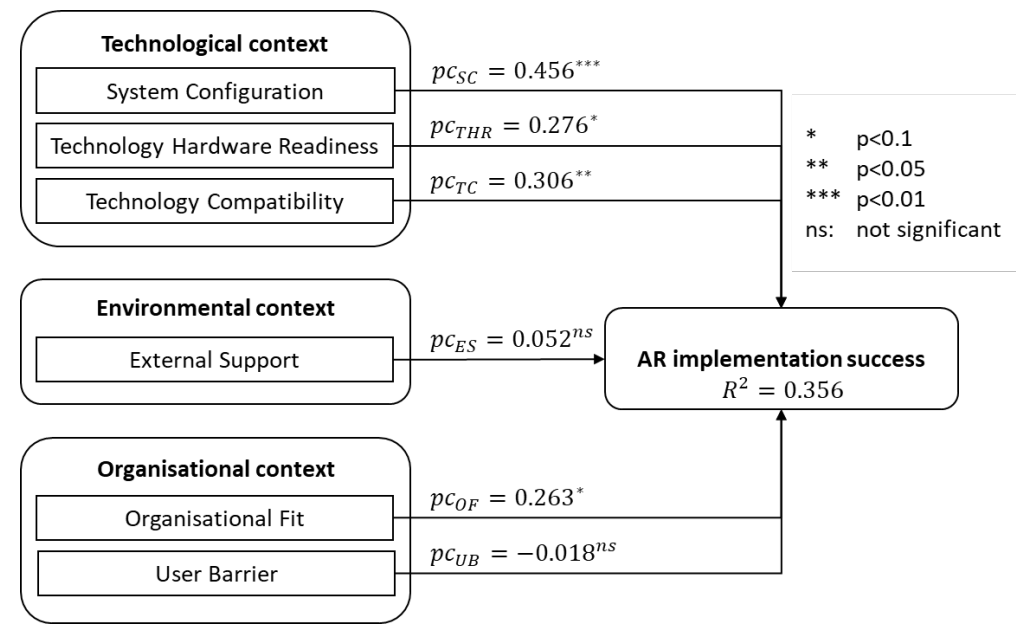

Fig 4 Results of the PLS-SEM: Path coefficients, significance level, and $R^{2}$ measure

The results show that the latent variables explain $35.6 \%$ of the variance in the dependent variable. Hence, the model is successful in explaining AR implementation success. Similar studies show similar results for $R^{2}$ [84]. Other models were tested as well to explore if a different configuration could explain the dependent variable to a higher extent. The main focus lied on combining the constructs of first-order constructs [66]. However, the results did not improve.

All three latent variables rooted in the technology context, namely system configuration $\left(p c_{S C}=0.456, p<0.01\right)$, technology hardware readiness $\left(p c_{T H R}=0.276, p<0.1\right)$, and technology compatibility $\left(p c_{T C}=0.306, p<0.05\right)$, significantly influence the AR implementation success. Thus, Hypothesis 1, Hypothesis 2, and Hypothesis 3 are accepted. Hypothesis 4, however, is rejected, as the influence of external support $\left(p c_{E S}=0.052, p>0.1\right)$ on the dependent variable is not significant. Additionally, hypothesis 6 is rejected, as the user barrier $\left(p c_{U B}=-0.018, p>0.1\right)$ does not have a significant path coefficient. The organisational fit $\left(p c_{O F}=0.263, p<0.1\right)$ is positively and significantly connected to the independent variable. Thus, Hypothesis 5 is accepted. In general, the technological context has the highest influence on the AR implementation success. Table sums up the results of the hypotheses testing. 


\begin{tabular}{llccc}
\hline \multicolumn{1}{c}{ Hypotheses } & Path Coefficient & Significance & Result \\
\hline H1 $\quad \begin{array}{l}\text { The system configuration is positively associated with the } \\
\text { implementation success of AR systems. }\end{array}$ & 0.456 & p $<0.01$ & accepted \\
H2 $\quad \begin{array}{l}\text { The technology hardware readiness is positively associated } \\
\text { with the implementation success of AR systems. }\end{array}$ & 0.276 accepted \\
H3 $\quad \begin{array}{l}\text { The technology compatibility is positively associated with the } \\
\text { implementation success of AR systems. }\end{array}$ & 0.306 & 0.052 & not significant & rejected \\
H4 $\quad \begin{array}{l}\text { External support is positively associated with the } \\
\text { implementation success of AR systems. }\end{array}$ & 0.263 & p<0.1 \\
H5 $\quad \begin{array}{l}\text { The organisational fit is positively associated with the } \\
\text { implementation success of AR systems. }\end{array}$ & $\begin{array}{l}\text { accepted } \\
\text { User barrier is negatively associated with the implementation } \\
\text { success of AR systems. }\end{array}$ & -0.018 & not significant & rejected \\
\hline
\end{tabular}

\subsection{Qualitative Results}

The qualitative results are analysed to determine if any important factors were not considered in the quantitative study and to conduct a validation of the quantitative results. The selection and ranking of the success factors were conducted by counting the number of selections. As the number of success factors selected varies, the rank is normalised in the range $[1,2]$, where 1 is the most important success factor. Then, the average of the normalised ranks of each item is calculated. Those two metrics are then used to plot the success factors on a chart (see Fig 5), where the $x$-axis represents the absolute number of how often a success factor was chosen and the $\mathrm{Y}$-axis the average normalised rank. A low rank correlates to a high importance Each dot on the chart represents one success factor. The lower the average rank, the higher is the importance of the success factor. The higher the count, the higher is the importance of the success.

The items are classified into four different quadrants. Quadrant 1 includes the factors with a low average rank and a high count, thus, the most important factors. In quadrant two, the count is lower compared to quadrant one, but the rank is similar. The factors in quadrant two are relatively unimportant with a low count and a high rank. No factors are in quadrant 4.

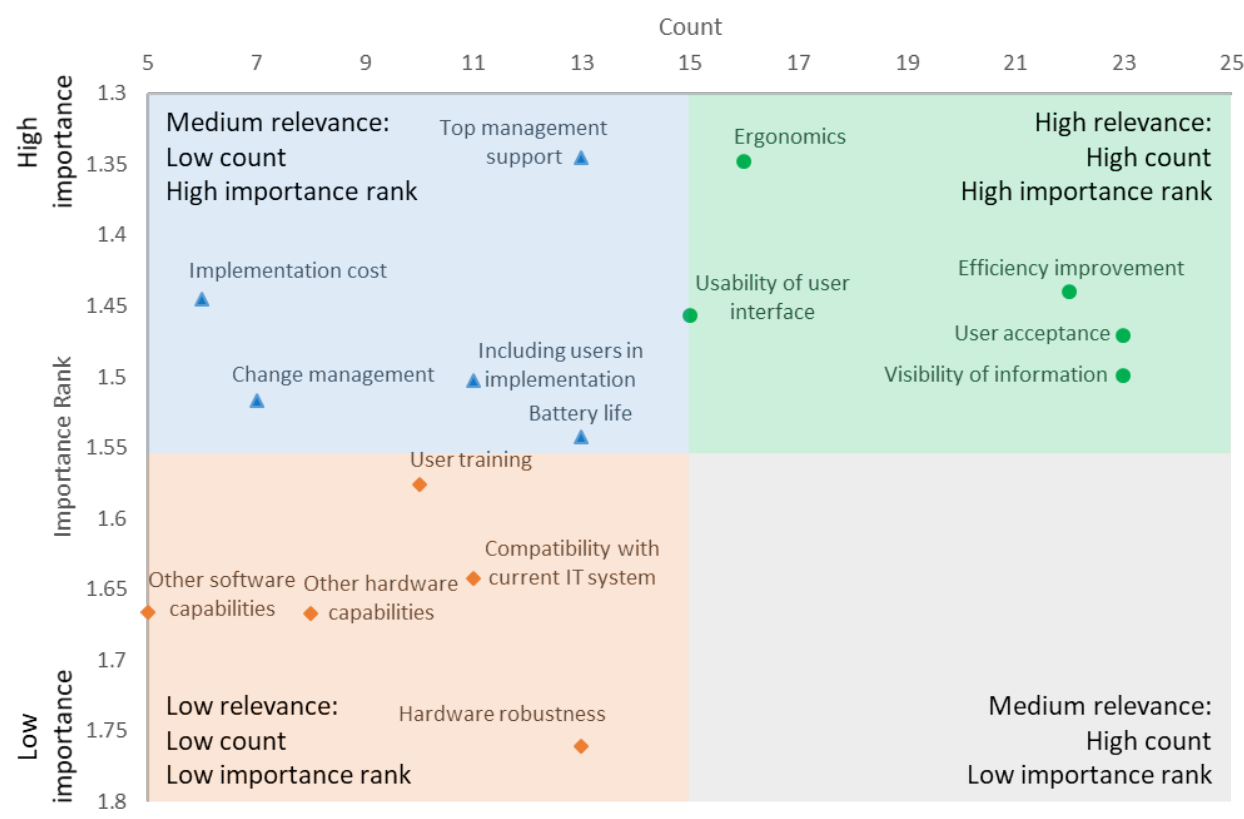

- High Relevance $\Delta$ Medium Relevance $\diamond$ Low Relevance

Fig 5 Success factors - average normalised rank and count for each of the success factor items provided in a multiple choice and following ranking question. 
A total of nine additional success factors were mentioned by survey participants. However, six additional can be attributed to one of the success factors above and, thus, were treated accordingly. These factors and the classification based on the given answers are:

- User interface design: Usability of user interface

- Tracking accuracy: Other software capabilities

- Weight (for HMDs): Ergonomics

- Rendering precision: Other software capabilities

- Ergonomics: Ergonomics

- Spatial mapping: Other software capabilities

Compared to the selection, three additional success factors were mentioned by survey participants:

- Thermal management of HMD

- $\quad$ Robust voice control

- Scalability

The answers to the open question concerning the challenges were categorised. The categories are based on the TOE framework and an extensive literature review [3]. A selection of those studies utilising field experiments to test AR systems and the challenges they encountered are listed in Table 1. However, new categories are based on terms that emerge from the data are used [11]. Fig 6 shows the results. The white boxes indicate relatively how often a certain challenge was mentioned. The left box indicates how often it was mentioned in the qualitative part of the survey (X\%). The right box shows how often it was mentioned in the 90 papers selected through a systematic literature review in [3] (Y\%). The green categories (scalability and software robustness) emerged from the survey results.

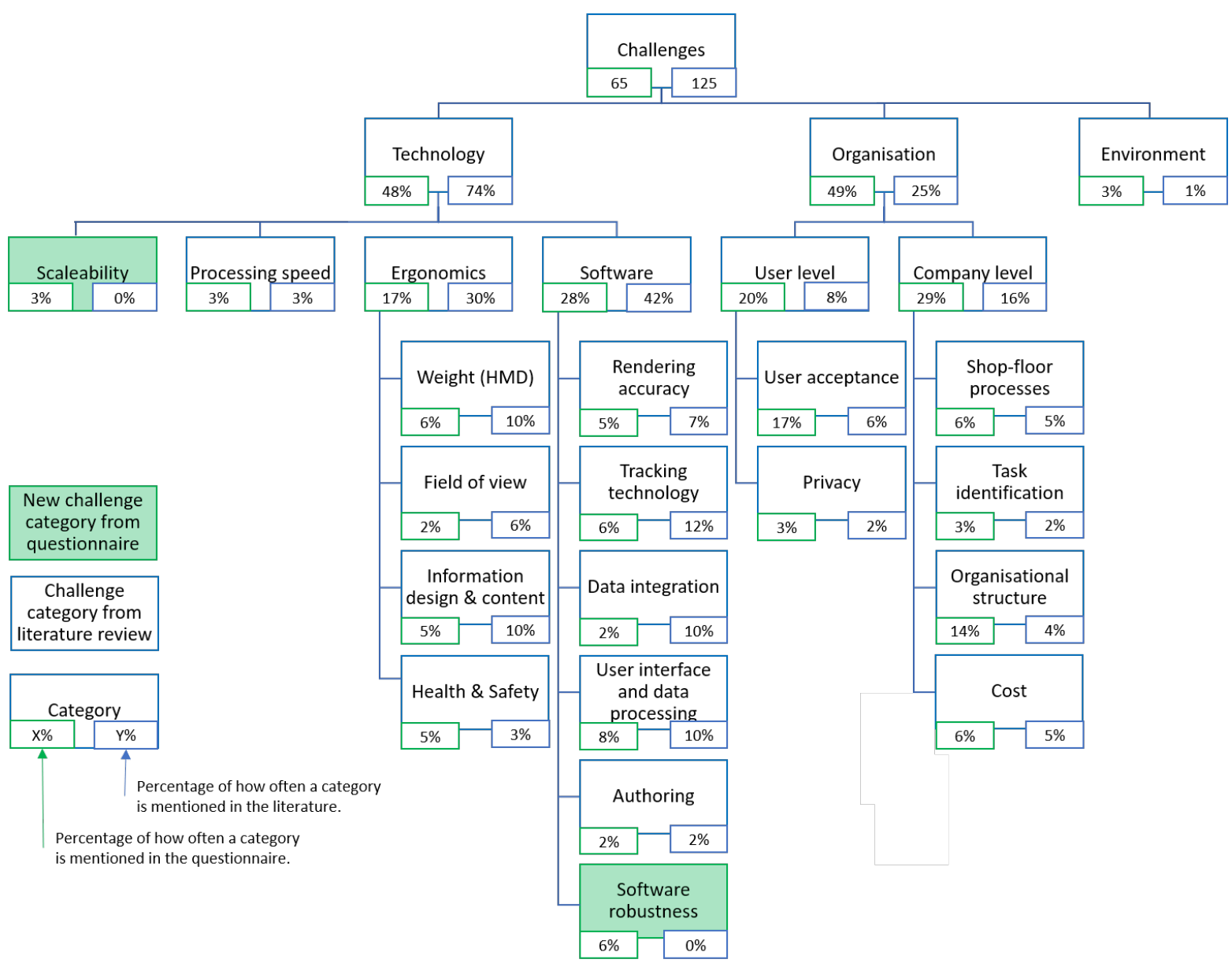

Fig 6 Categorisation of challenges. The white rectangles at each category indicate the occurrences of the category. The left rectangle ( $X \%$ category) shows how often it was mentioned in the survey. The right rectangle (Y\% category) shows how often it was mentioned in a review of 90 papers [3]. 


\section{Discussion}

In this section, the results of the qualitative and the quantitative part of the questionnaire are discussed and compared. Additionally, a comparison to the challenges uncovered in research is conducted. Then, implications for academia and industry are outlined as well as limitations of the study and possibilities for further work.

The external support has no statistically significant influence on the implementation success. This has been observed in other studies concerned with implementation success [66] or Industry 4.0 adoption [76] as well. Several possible explanations for this issue exist, for example:

- Companies may not use industry associations to develop and promote de-facto industry standards, as the technology is fairly young and such information might be seen as proprietary.

- External support might be crucial in the adoption decision-making process itself, prior to the actual implementation stage. At this initial stage of the adoption decision, companies might not be equipped with an appropriate level of AR knowledge, as it is a new technology. Hence, the influence at the adoption stage concerning external support to build up the necessary knowledge base could be significant.

Despite the fact that the user barriers do not correlate with the implementation success in this study, this doesn't mean that they are not important. Especially when comparing the quantitative results with the qualitative results concerning user acceptance, the difference is striking. Fig 5 and Fig 6 show that the user acceptance is an important challenge and a significant success factor respectively. Fig 5 shows that the success factors concerned with making the technology work for the users of the AR system are crucial. The success factors in the top right quadrant (quadrant 1), namely user acceptance, visibility of information, efficiency improvement, ergonomics, and usability of the user interface, are the most important ones and all except the efficiency improvement user-centric. Yet, the quantitative part does not support these statements. There are several possible explanations for why that is the case:

- As people involved with AR implementation and pilot projects are aware of the issue of user acceptance, it is addressed and resolved at an early stage of the implementation and pilot project, thus, rendering the result of the project independent to the initial user barriers, due to e.g. mistrust towards the technology (measure UB 2 of the construct).

- It might be that the implementation success is independent of that construct, as it measures the willingness to further work with the technology [33]. Despite the fact that there are user barriers, people might still see the potential of the technology and are willing to pursue it further in the firm conviction that the user barriers will be overcome at some point.

- The construct might not be completely aligned with the understanding of user acceptance in the qualitative questions. While it has been discussed to incorporate the user perspective more into the TOE, it might be that the approach needs to be expanded to align another framework, like the TAM with the TOE on a more fundamental basis.

The organisational fit and the constructs within the technological construct influence the implementation success significantly. The technological constructs have the biggest impact. However, the qualitative results from concerning the challenges indicate that most of the challenges industry is concerned with stem from an organisational point of view (see Fig 6) compared to academic research, which tends to have a technological focus. While the technological capabilities seem to be the basis for making the implementation work (see Fig 4), the organisational challenges to overcome are a substantial concern for the industry.

\subsection{Implications for Academia}

This study used the TOE framework to determine the effects of different factors in the implementation success. The quantitative part indicated factors that influence the implementation success and shows the empirical applicability of the TOE framework for AR solutions. Hence, this framework can also be used for other technologies in the Industry 4.0 context to promote implementation efforts.

While this study shows that the technological context is the basis for a successful AR implementation, the organisational side of the implementation is crucial for the industry as well. Compared to a selection of academic papers analysed through a systematic literature review [3] (see Fig 6), academia focuses more on the technical challenges than the organisational challenges ones, while industry focuses more on organisational issues.

The combination of quantitative and qualitative information enabled the critical discussion of the quantitative data and the extension of the TOE framework towards also implementing user-centric views [88, 89]. Especially the external support and the user-centric view could be examined by future research, as we acknowledge that those might have an influence at another innovation stage or by utilising a combination of the TOE and another user-centric framework, like the TAM.

\subsection{Implications for Practice}

The study unveils the areas that are crucial to AR project success. Hence, it holds relevant implications for organisations seeking to implement industrial augmented reality. 
To ensure success, it is important to conduct a critical assessment if the technology is ready for a certain task or not. While AR hardware is ready for deployment in some areas, it might lack the maturity to be deployed for other, more demanding tasks. Based on the literature review, it became apparent that AR is already broadly used in warehouse operations, especially picking. For more complex tasks and challenging industrial environments, there might be technological issues still posing a barrier.

Due to the complexity of industrial systems and the relatively early stage in the lifecycle of AR, there are no out of the box solutions available and there may very well be one fits all system. The technology needs to be tested sufficiently to ensure it is configured in a suitable manner. A large number of hardware systems available. The organisation needs to make sure that the hardware is capable to fulfil the task and does not put too much ergonomic strain on employees.

AR systems need to be tied in with the current IT infrastructure to allow for real-time information transmission [60]. Hence, the compatibility with the current IT system is an important factor. In broader terms, the AR system needs to be aligned with the current practice of the company, be it IT, processes, or health and safety.

Organisations should ensure a fit between the technology and the organisation itself. AR can only unfold its full potential if the process supported by AR is adapted to the technology. For assembly operations, for example, this could mean adapting the information flow towards and from the assembly line or increasing the flexibility in creating shift schedules. Additionally, employees need to be prepared for the new technology, especially on the user level. They need to be familiarised with the new technology and changes to the process during the implementation to effectively and efficiently utilise the system. During pilot studies, workers who will use the AR system might also be a valuable source of input concerning usability and ergonomics as those are highly relevant factors (see Fig 5 and Fig 6).

\subsection{Limitations and Further Work}

While having significant implications for academia and practice, this study also has limitations, which indicate directions for future research.

The qualitative part of the study unveiled some factors that have not been part of the quantitative study. Especially the scalability of the AR solution seems to be of interest for industry, as it has been mentioned in the challenges and the success factors question for the current pilot- and implementation projects. Scalability can be part of a 'relative advantage' construct in the technology context [89] for future TOE framework based research.

Hypothesis 4 and 6 were found to be insignificant, which introduces interesting new research opportunities as the qualitative results to some extent contrast the quantitative results. Future studies can utilise acceptance models on a user level into a TOE-based research project to ground these factors in theory and determine their influence. Especially as AR also includes new hardware and can change work processes, the user side needs to be analysed in more detail.

AR is a fairly new technology in the industry without widespread adoption. The capabilities of the technology are still important, as it has not reached maturity yet. However, there seems to be a tendency according to the qualitative results that the technology is not as important as organisational issues when implementing the technology in industrial settings. This shift from a technology focus to an organisational focus, however, does not seem to be reflected in the AR research (see Fig 6). Due to the significant implications of the organisational fit and the compatibility of the technology towards implementation success, future research can focus on how to adapt processes for AR, how to align it with the current systems, or how to ensure the operator's health and safety when using those systems.

It has to be noted, however, that focusing on the identified challenges and success factors do not essentially guarantee success when implementing AR. Some factors were unveiled in the qualitative part, but it is unclear how strong their influence is. In addition, other factors related to different contexts might exist. Those can be relevant to AR implementation as well and might also be industry or application specific and could also stem from the company environment. Hence, further research could focus on different applications or industries and the challenges when implementing AR systems there. 


\section{Conclusion}

Industrial AR is a central part of Industry 4.0 initiatives. It enables workers to be smoothly integrated into the digital environment. The aim of this study was to answer the research question 'Which factors influence the implementation success of industrial augmented reality?', by utilising a quantitative questionnaire based on the TOE framework and targeted towards professionals who have been involved with industrial AR pilot or implementation projects. This part was supplemented by a qualitative part focusing on challenges and success factors.

This paper has contributed to the academic and industrial bodies of knowledge through three main aspects. First, the TOE framework has been used for a variety of Industry 4.0 technologies (see Table 2). Through the quantitative part and the qualitative categorisation according to the TOE model, this study has expanded on the body of knowledge for TOE based research and Industry 4.0 relevant technologies. Second, we utilised a quantitative and a qualitative perspective towards AR implementation. Based on those two pillars, the results from industry professionals allowed us to analyse and uncover challenges and success factors on a broad basis. Finally, this paper provides guidance on which aspects industry should focus on to ensure implementation success. As the number of implementation projects of industrial AR is expected to increase over the next years, a rising number of companies will be subjected to the issues presented in this paper. Our study has suggested that technological factors and the organisational fit are critical for the success of AR in industry 4.0 initiatives.

\section{Acknowledgements}

This research was supported and funded by the University of Cambridge. The authors are most grateful to the participants of the industrial survey, reviewers and colleagues for their constructive and helpful comments.

\section{References}

[1] R. Davies, Industry 4.0: Digitalisation for productivity and growth (2015)

[2] BIS Research, Global Augmented Reality and Mixed Reality Market: Analysis Forecast 2018-2025 (2018)

[3] J. Egger, T. Masood, Augmented Reality in Support of Intelligent Manufacturing - A Structured Literature Review. Journal of Intelligent Manufacturing. Submitted (2018)

[4] T. Bosch, R. Könemann, H. de Cock et al., The effects of projected versus display instructions on productivity, quality and workload in a simulated assembly task Proceedings of the 10th International Conference on Pervasive Technologies Related to Assistive Environments (2017) 412-415.

[5] S. J Henderson, S. K Feiner, Augmented reality in the psychomotor phase of a procedural task 10th IEEE International Symposium on Mixed and Augmented Reality (ISMAR), 2011 (2011) 191-200.

[6] J. Hahn, B. Ludwig, C. Wolff, Augmented reality-based training of the PCB assembly process Proceedings of the 14th International Conference on Mobile and Ubiquitous Multimedia (2015) 395-399.

[7] A. Sanna, F. Manuri, F. Lamberti et al., Using handheld devices to support augmented reality-based maintenance and assembly tasks IEEE International Conference on Consumer Electronics (ICCE), 2015 (2015) 178-179.

[8] M. Funk, T. Kosch, A. Schmidt, Interactive worker assistance Proceedings of the 2016 ACM International Joint Conference on Pervasive and Ubiquitous Computing (2016) 934-939.

[9] M. Funk, A. Bächler, L. Bächler et al., Working with Augmented Reality?: A Long-Term Analysis of In-Situ Instructions at the Assembly Workplace Proceedings of the 10th International Conference on Pervasive Technologies Related to Assistive Environments (2017) 222-229.

[10] R. DePietro, E. Wiarda, M. Fleischer, The context for change: Organization, technology and environment The processes of technological innovation (1990) 151-175.

[11] M. Saunders, P. Lewis, A. Thornhill, Research methods for business student: fifth Edition (2009). Pearson Education, Harlow.

[12] H. Kagermann, W. Wahlster, J. Helbig, Umsetzungsempfehlungen für das Zukuntsprojekt Industrie 4.0: Abschlussbericht des Arbeitskreises Industrie 4.0 (2013)

[13] P. Milgram, K. Takemura, A. Utsumi et al., Augmented Reality: A class of displays on the reality-virtuality continuum. Telemanipulator and Telepresence Technologies (1994) 282-2802.

[14] A.Y.C. Nee, S. K. Ong, G. Chryssolouris et al., Augmented reality applications in design and manufacturing. CIRP Annals Manufacturing Technology, 61, 2 (2012) 657-79.

[15] S. Werrlich, K. Nitsche, G. Notni, Demand Analysis for an Augmented Reality based Assembly Training Proceedings of the 10th International Conference on Pervasive Technologies Related to Assistive Environments (2017) 416-422.

[16] J. Blattgerste, B. Strenge, P. Renner et al., Comparing Conventional and Augmented Reality Instructions for Manual Assembly Tasks Proceedings of the 10th International Conference on Pervasive Technologies Related to Assistive Environments (2017) 75-82.

[17] P. Han, G. Zhao, Line-based initialization method for mobile augmented reality in aircraft assembly. The Visual Computer, 33 (2017) 1185-1196.

[18] W. A Günthner, N. Blomeyer, R. Reif et al., Pick-by-Vision: Augmented Reality unterstützte Kommissionierung (2009). Lehrstuhl für Fördertechnik Materialfluß Logistik (fml) Techn. Univ. München, Garching. 
[19] R. Reif, W. A Guenther, B. Schwerdtfeger et al., Pick-by-vision comes of Age: Evaluation of an augmented reality supported picking system in real storage environment Proceedings of the 6th International Conference on Computer Graphics, Virtual Reality, Visualisation and Interaction (2009) 23-32.

[20] R. Reif, W. A Günthner, Pick-by-vision: Augmented reality supported order picking. The Visual Computer, 25 (2009) 461-467.

[21] R. Hanson, W. Falkenström, M. Miettinen, Augmented reality as a means of conveying picking information in kit preparation for mixed-model assembly. Computers \& Industrial Engineering, 113 (2017) 570-575.

[22] A. Guo, T. Starner, S. Raghu et al., A comparison of order picking assisted by head-up display (HUD), cart-mounted display (CMD), light, and paper pick list Proceedings of the 2014 ACM International Symposium on Wearable Computers (2014) 71-78.

[23] P. Renner, T. Pfeiffer, Augmented Reality Assistance in the Central Field-of-View Outperforms Peripheral Displays for Order Picking: Results from a Virtual Reality Simulation Study 2017 IEEE International Symposium on Mixed and Augmented Reality (ISMAR-Adjunct) (2017) 176-181.

[24] M.-H. Stoltz, V. Giannikas, D. McFarlane et al., Augmented Reality in Warehouse Operations: Opportunities and Barriers. IFAC-PapersOnLine, 50 (2017) 12979-12984.

[25] D. Antonelli, S. Astanin, Enhancing the Quality of Manual Spot Welding through Augmented Reality Assisted Guidance. Procedia CIRP, 33 (2015) 556-561.

[26] D. Segovia, M. Mendoza, E. Mendoza et al., Augmented Reality as a Tool for Production and Quality Monitoring. Procedia Computer Science, 75 (2015) 291-300.

[27] S. Sauer, D. Berndt, J. Schnee et al., Worker Assistance and Quality Inspection: Application of Optical 3D Metrology and Augmented Reality Technologies 14th Joint International IMEKO TC1, TC7, TC13 Symposium on Intelligent Quality Measurements - Theory (2011) 112-113.

[28] A. Martinetti, M. Rajabalinejad, L. van Dongen, Shaping the Future Maintenance Operations: Reflections on the Adoptions of Augmented Reality Through Problems and Opportunities. Procedia CIRP, 59 (2017) 14-17.

[29] R. Masoni, F. Ferrise, M. Bordegoni et al., Supporting Remote Maintenance in Industry 4.0 through Augmented Reality. Procedia Manufacturing, 11 (2017) 1296-1302.

[30] D. Mourtzis, V. Zogopoulos, E. Vlachou, Augmented Reality Application to Support Remote Maintenance as a Service in the Robotics Industry. Procedia CIRP, 63 (2017) 46-51.

[31] R. Palmarini, J. A Erkoyuncu, R. Roy, An Innovative Process to Select Augmented Reality (AR) Technology for Maintenance. Procedia CIRP, 59 (2017) 23-28.

[32] M. Fiorentino, R. Radkowski, A. Boccaccio et al., Magic Mirror Interface for Augmented Reality Maintenance the International Working Conference (2016) 160-167.

[33] J. Zhu, S. K Ong, A. YC Nee, An authorable context-aware augmented reality system to assist the maintenance technicians. The International Journal of Advanced Manufacturing Technology, 45 (2012) 1699-1714.

[34] N. Soete, A. Claeys, S. Hoedt et al., Towards Mixed Reality in SCADA Applications. IFAC-PapersOnLine, 48 (2015) 24172422.

[35] T. Masood, J. Egger, M. Kern, Future-proofing the Through-life Engineering Service Systems. Procedia Manufacturing, 16 (2018) 179-186.

[36] D. Mourtzis, V. Zogopoulos, I. Katagis et al., Augmented Reality based Visualization of CAM Instructions towards Industry 4.0 paradigm: a CNC Bending Machine case study, 28th CIRP Design conference, 23-25 May, Nantes, France (2018) 368-373.

[37] S. Makris, P. Karagiannis, S. Koukas et al., Augmented reality system for operator support in human-robot collaborative assembly. CIRP Annals - Manufacturing Technology, 65, 1 (2016) 61-64.

[38] G. Michalos, N. Kousi, P. Karagiannis et al., Seamless human robot collaborative assembly - an automotive case study. Mechatronics (2018) 1-18, https://doi.org/10.1016/j.mechatronics.2018.08.006.

[39] R. Palmarini, J.A. Erkoyuncu, R. Roy, H. Torabmostaedi, A systematic review of augmented reality applications in maintenance, Robot. Comput. Integr. Manuf. 49 (2018) 215-228. doi:10.1016/j.rcim.2017.06.002.

[40] M. Gattullo, G.W. Scurati, M. Fiorentino, A.E. Uva, F. Ferrise, M. Bordegoni, Towards augmented reality manuals for industry 4.0: A methodology, Robot. Comput. Integr. Manuf. 56 (2019) 276-286. doi:https://doi.org/10.1016/j.rcim.2018.10.001.

[41] A.W.W. Yew, S.K. Ong, A.Y.C. Nee, Towards a griddable distributed manufacturing system with augmented reality interfaces, Robot. Comput. Integr. Manuf. 39 (2016) 43-55. doi:10.1016/j.rcim.2015.12.002.

[42] E. Matsas, G.-C. Vosniakos, D. Batras, Prototyping proactive and adaptive techniques for human-robot collaboration in manufacturing using virtual reality, Robot. Comput. Integr. Manuf. 50 (2018) 168-180. doi:https://doi.org/10.1016/j.rcim.2017.09.005.

[43] X. Wang, S.K. Ong, A.Y.C. Nee, Real-virtual components interaction for assembly simulation and planning, Robot. Comput. Integr. Manuf. 41 (2016) 102-114. doi:https://doi.org/10.1016/j.rcim.2016.03.005.

Masood, T. and Egger, J. (2019) 'Augmented Reality in support of Industry 4.0 - Implementation Challenges and Success Factors', Robotics and Computer Integrated Manufacturing, in press, 25 pages, https://doi.org/10.1016/j.rcim.2019.02.003. Page | 21 
[44] H.C. Fang, S.K. Ong, A.Y.C. Nee, Interactive robot trajectory planning and simulation using Augmented Reality, Robot. Comput. Integr. Manuf. 28 (2012) 227-237. doi:https://doi.org/10.1016/j.rcim.2011.09.003.

[45] J.W.S. Chong, S.K. Ong, A.Y.C. Nee, K. Youcef-Youmi, Robot programming using augmented reality: An interactive method for planning collision-free paths, Robot. Comput. Integr. Manuf. 25 (2009) 689-701. doi:https://doi.org/10.1016/j.rcim.2008.05.002.

[46] M. Holm, O. Danielsson, A. Syberfeldt et al., Adaptive instructions to novice shop-floor operators using Augmented Reality. Journal of Industrial and Production Engineering, 34 (2017) 362-374.

[47] A. Syberfeldt, M. Holm, O. Danielsson et al., Support Systems on the Industrial Shop-floors of the Future - Operators' Perspective on Augmented Reality. Procedia CIRP, 44 (2016) 108-113.

[48] Y. Wang, S. Zhang, S. Yang et al., Mechanical assembly assistance using marker-less augmented reality system. Assembly Automation, 38 (2018) 77-87.

[49] L.-C. Wu, I.-C. Lin, M.-H. Tsai, Augmented reality instruction for object assembly based on markerless tracking Proceedings of the 20th ACM SIGGRAPH Symposium (2016) 95-102.

[50] M. Majewski, W. Kacalak, Human-Machine Speech-Based Interfaces with Augmented Reality and Interactive Systems for Controlling Mobile Cranes Interactive Collaborative Robotics (2016) 89-98.

[51] Z. Zhou, A. D Cheok, Y. Qiu et al., The Role of 3-D Sound in Human Reaction and Performance in Augmented Reality Environments. IEEE Transactions on Systems, Man, and Cybernetics - Part A: Systems and Humans, 37 (2007) 262-272.

[52] R. Radkowski, C. Stritzke, Interactive Hand Gesture-based Assembly for Augmented Reality Applications ACHI 2012 (2012) 303-308.

[53] X. Wang, S. K Ong, A. Nee, Multi-modal augmented-reality assembly guidance based on bare-hand interface. Advanced Engineering Informatics, 30 (2016) 526-421.

[54] H. M Park, S. H Lee, J. S Choi, Wearable Augmented Reality System using Gaze Interaction 7th IEEE/ACM International Symposium on Mixed and Augmented Reality, 2008 (2008) 175-176.

[55] N. Murauer, N. Pflanz, C. von Hassel, Comparison of Scan-Mechanisms in Augmented Reality-Supported Order Picking Processes. CEUR Workshop Proceedings, 2082 (2018) 69-76.

[56] YouGov, YouGov Virtual Reality (2018). https://today.yougov.com/find-solutions/insights/yougov-reports/virtualreality/, Accessed 03 Jul 2018.

[57] L. Hou, X. Wang, A study on the benefits of augmented reality in retaining working memory in assembly tasks: A focus on differences in gender. Automation in Construction, 32 (2013) 38-45.

[58] D. Mourtzis, A. Vlachou, V. Zogopoulos, Cloud-Based Augmented Reality Remote Maintenance Through Shop-Floor Monitoring: A Product-Service System Approach. Journal of Manufacturing Science and Engineering, 139 (2017) 1-11.

[59] J. Real, L. Marcelino, Augmented Reality Systems for Inventorying 6th Iberian Conference on Information Systems and Technologies (CISTI), 2011 (2011) 1-9.

[60] J. Serván, F. Mas, J. L Menéndez et al., Assembly Work Instruction Deployment Using Augmented Reality. Key Engineering Materials, 502 (2012) 25-30.

[61] I. Porcelli, M. Rapaccini, D. B Espíndola et al., Technical and Organizational Issues about the Introduction of Augmented Reality in Maintenance and Technical Assistance Services. IFAC Proceedings Volumes, 46 (2013) 257-262.

[62] N. Gavish, T. Gutiérrez, S. Webel et al., Evaluating virtual reality and augmented reality training for industrial maintenance and assembly tasks. Interactive Learning Environments, 23 (2013) 778-798.

[63] A. Doshi, R. T Smith, B. H Thomas et al., Use of projector based augmented reality to improve manual spot-welding precision and accuracy for automotive manufacturing. The International Journal of Advanced Manufacturing Technology, 89 (2017) 1279-1293.

[64] Tornatzky LG, Fleischer M (eds) (1990), The processes of technological innovation. Issues in organization and management series. Lexington Books, Lexington Mass.

[65] K. Zhu, K. L Kraemer, Post-Adoption Variations in Usage and Value of E-Business by Organizations: Cross-Country Evidence from the Retail Industry. Information Systems Research, 16 (2005) 61-84.

[66] Y. Zhu, Y. Li, W. Wang et al., What leads to post-implementation success of ERP?: An empirical study of the Chinese retail industry. International Journal of Information Management, 30 (2010) 265-276.

[67] Q. Jia, Y. Guo, S. J Barnes, Enterprise 2.0 post-adoption: Extending the information system continuance model based on the technology-Organization-environment framework. Computers in Human Behavior, 67 (2017) 95-105.

[68] C.-P. Lee, J. P Shim, An exploratory study of radio frequency identification (RFID) adoption in the healthcare industry. European Journal of Information Systems, 16 (2017) 712-724.

[69] A. Scupola, The Adoption of Internet Commerce by SMEs in the South of Italy: An Environmental, Technological and Organizational Perspective. Journal of Global Information Technology Management, 6 (2014) 52-71.

[70] A. N Mishra, P. Konana, A. Barua, Antecedents and Consequences of Internet Use in Procurement: An Empirical Investigation of U.S. Manufacturing Firms. Information Systems Research, 18 (2007) 103-120.

[71] Y.-M. Wang, Y.-S. Wang, Y.-F. Yang, Understanding the determinants of RFID adoption in the manufacturing industry. Technological Forecasting and Social Change, 77 (2010) 803-815.

Masood, T. and Egger, J. (2019) 'Augmented Reality in support of Industry 4.0 - Implementation Challenges and Success Factors', Robotics and Computer Integrated Manufacturing, in press, 25 pages, https://doi.org/10.1016/j.rcim.2019.02.003. 
[72] A. Abdollahzadehgan, A. RC Hussin, M. M Gohary et al., The Organizational Ciritical Success Factors for Adopting Cloud Computing in SMEs. JISRI (2013) 67-74.

[73] Y. K Dwivedi, B. Ramdani, P. Kawalek et al., Predicting SMEs' adoption of enterprise systems. Journal of Enterprise Information Management, 22 (2009) 10-24.

[74] K. N Kumar, S. Chandra, S. Bharati et al., Factors influencing adoption of augmented reality technology for ecommerce PACIS proceedings 2016 1-9.

[75] E. M Rogers, Diffusion of innovations, 4. ed. (1995). Free Press, New York, NY u. a.

[76] C. Arnold, J. Veile, K.-I. Voigt, What Drives Industry 4.0 Adoption? An Examination of Technological, Organizational, and Environmental Determinants IAMOT Conference (2018) 1-19.

[77] S. Sun, C. G Cegielski, L. Jia et al., Understanding the Factors Affecting the Organizational Adoption of Big Data. Journal of Computer Information Systems, 58 (2016) 193-203.

[78] C.-C. Yeh, Y.-F. Chen, Critical success factors for adoption of 3D printing. Technological Forecasting and Social Change, 132 (2018) 209-216.

[79] F. D Davis (1985), A Technology Acceptance Model for Empirically Testing New End-Uster Information Systems: Theory and Resulty. Ph.D. Thesis, Massachusetts Institute of Technology

[80] F. D Davis, R. P Bagozzi, P. R Warshaw, User Acceptance of Computer Technology: A Comparison of Two Theoretical Models. Management Science, 35 (1989) 982-1003.

[81] V. Venkatesh, M. G Morris, G. B Davis et al., User Acceptance of Information Technology: Toward a Unified View. MIS Quarterly, 27 (2003) 425-478.

[82] J. Wei, P. B Lowry, S. Seedorf, The assimilation of RFID technology by Chinese companies: A technology diffusion perspective. Information \& Management, 52 (2015) 628-642.

[83] I. Ajzen, The theory of planned behavior. Organizational Behavior and Human Decision Processes, 50 (1991) 179-211.

[84] T. Oliveira, M. Thomas, M. Espadanal, Assessing the determinants of cloud computing adoption: An analysis of the manufacturing and services sectors. Information \& Management, 51 (2014) 497-510.

[85] N. Marangunić, A. Granić, Technology acceptance model: A literature review from 1986 to 2013. Universal Access in the Information Society, 14 (2015) 81-95.

[86] T. Jung, Dieck, Claudia, M. T., D. T Dieck, A Theoretical Model of Augemented Reality Acceptance (2014)

[87] T.-L. Huang, S. Liao, A model of acceptance of augmented-reality interactive technology: The moderating role of cognitive innovativeness. Electronic Commerce Research, 15 (2015) 269-295.

[76] J. Baker, The Technology-Organization-Environment Framework Information Systems Theory, 28 (2012) 231-245.

[89] H. Gangwar, H. Date, R. Ramaswamy, Understanding determinants of cloud computing adoption using an integrated TAM-TOE model. Journal of Enterprise Information Management, 28 (2015) 107-130.

[90] A. Gonçalves, L. Nascimento, M. Bouzada et al., Factors that Influence the Adoption and Implementation of Public Digital Accounting According to the Evaluation by Managers of Brazilian Companies. Journal of Information Systems and Technology Management, 13 (2016) 193-218.

[91] K. Zhu, K. L Kraemer, S. Xu, The Process of Innovation Assimilation by Firms in Different Countries: A Technology Diffusion Perspective on E-Business. Management Science, 52 (2006) 1557-1588.

[92] P. Chwelos, I. Benbasat, A. S Dexter, Research Report: Empirical Test of an EDI Adoption Model. Information Systems Research, 12 (2001) 304-321.

[93] K. Zhu, K. L Kraemer, S. Xu et al., Information Technology Payoff in E-Business Environments: An International Perspective on Value Creation of E-Business in the Financial Services Industry. Journal of Management Information Systems, 21 (2004) 17-54.

[94] D. B Espíndola, L. Fumagalli, M. Garetti et al., A model-based approach for data integration to improve maintenance management by mixed reality. Computers in Industry, 64 (2013) 376-391.

[95] T. Engelke, J. Keil, P. Rojtberg et al., Content First - A concept for Industrial Augmented Reality Maintenance Applications using Mobilde Devices Proceedings of the 6th ACM Multimedia Systems Conference (2015) 105-111.

[96] J. Haase, D. Beimborn, Acceptance of Warehouse Picking Systems Proceedings of the 2017 ACM SIGMIS Conference (2017) 53-60.

[97] A. E Uva, M. Gattullo, V. M Manghisi et al., Evaluating the effectiveness of spatial augmented reality in smart manufacturing: A solution for manual working stations. The International Journal of Advanced Manufacturing Technology, 94 (2018) 509-521.

[98] V. Kretschmer, T. Plewan, G. Rinkenauer et al., Smart palletisation: Cognitive ergonomics in augmented reality based palletising 1st International Conference on Intelligent Human Systems Integration, 722 (2018) 355-360.

[99] S. Alshawi, M. Themistocleous, R. Almadani, Integrating diverse ERP systems: A case study. Journal of Enterprise Information Management, 17 (2004) 454-462.

[100] A. Rashid, T. Masood, J. A Erkoyuncu et al., Enterprise systems' life cycle in pursuit of resilient smart factory for emerging aircraft industry: A synthesis of Critical Success Factors'(CSFs), theory, knowledge gaps, and implications. Enterprise Information Systems, 39 (2017) 1-41. 
[101] A. Syberfeldt, O. Danielsson, P. Gustavsson, Augmented Reality Smart Glasses in the Smart Factory: Product Evaluation Guidelines and Review of Available Products. IEEE Access, 5 (2017) 9118-9130.

[102] VDI, Augmented and Virtual Reality as Smart Assistance (2018). https://www.vdi-wissensforum.de/weiterbildungmaschinenbau/augmented-und-virtual-reality/, Accessed 12 Jul 2018.

[103] Yuan Y, IEEE P2048 Standards Paving the Road for Virtual Reality and Augmented Reality (2017). https://www.standardsuniversity.org/e-magazine/june-2017/ieee-p2048-standards-paving-road-virtual-realityaugmented-reality/, Accessed 30 Jun 2018.

[104] R. Angeles, Using the Technology-Organization-Environment Framework for Analyzing Nike's "Considered Index" Green Initiative, a Decision Support System-Driven System. Journal of Management and Sustainability, 4 (2014)

[105] G. Premkumar, A Meta-Analysis of Research on Information Technology Implementation in Small Business. Journal of Organizational Computing and Electronic Commerce, 13 (2003) 91-121.

[106] C. Wu, H. Wang, A Multi-Modal Augmented Reality Based Virtual Assembly System Proceedings of the International Conference on Human-centric Computing 2011 and Embedded and Multimedia Computing 2011, 102 (2011) 65-72.

[107] T. Oliveira, M. F Martins, Literature Review of Information Technology Adoption Models at Firm Level. The Electronic Journal Information Systems Evaluation, 14 (2011) 110-121.

[108] National Statistical Service, Sample Size Calculator (2018). http://www.nss.gov.au/nss/home.nsf/pages/Sample+size+calculator, Accessed 12 Jul 2018.

[109] J. F Hair, A primer on partial least squares structural equation modeling (PLS-SEM) (2014). p.125, SAGE Publ, Los Angeles.

[110] M. Sarstedt, E. Mooi, A Concise Guide to Market Research: The Process, Data, and Methods Using IBM SPSS Statistics, 2nd ed. 2014. Springer Texts in Business and Economics (2014)

[111] C. M Voorhees, M. K Brady, R. Calantone et al., Discriminant validity testing in marketing: An analysis, causes for concern, and proposed remedies. Journal of the Academy of Marketing Science, 44 (2016) 119-134.

[112] C. Fornell, D. F Larcker, Evaluating Structural Equation Models with Unobservable Variables and Measurement Error. Journal of Marketing Research, 18 (1981) 39-50. 


\begin{tabular}{|c|c|c|c|}
\hline Latent Variable & Source & Measure & Statement \\
\hline \multirow[t]{3}{*}{$\begin{array}{l}\text { Implementation } \\
\text { Success }\end{array}$} & \multirow[t]{3}{*}{$\begin{array}{l}\text { Zhu et al. 2010; Jia et al. } \\
2017\end{array}$} & IS1 & $\begin{array}{l}\text { My company is thinking about implementing AR } \\
\text { solutions in other sites. }\end{array}$ \\
\hline & & IS2 & $\begin{array}{l}\text { My company is thinking about implementing AR } \\
\text { solutions for other applications. }\end{array}$ \\
\hline & & IS3 & $\begin{array}{l}\text { My company got substantial benefits after the AR } \\
\text { solution became operational (for example cost savings). }\end{array}$ \\
\hline \multirow[t]{2}{*}{ System configuration } & \multirow[t]{2}{*}{$\begin{array}{l}\text { Zhu et al. 2006; Zhu et al. } \\
2010\end{array}$} & SC1 & $\begin{array}{l}\text { Pilot studies with different AR hardware were } \\
\text { conducted. }\end{array}$ \\
\hline & & SC2 & $\begin{array}{l}\text { The users of AR devices were trained before the } \\
\text { implementation. }\end{array}$ \\
\hline \multirow[t]{2}{*}{ User Barriers } & \multirow[t]{2}{*}{$\begin{array}{l}\text { Wu et al 2011; Gangwar } \\
\text { et al. } 2015\end{array}$} & UB1 & $\begin{array}{l}\text { The AR devices caused ergonomic problems, like } \\
\text { headaches. }\end{array}$ \\
\hline & & UB2 & Users of the AR system mistrusted the technology. \\
\hline \multirow[t]{2}{*}{$\begin{array}{l}\text { Technology hardware } \\
\text { readiness }\end{array}$} & \multirow{2}{*}{$\begin{array}{l}\text { Zhu et al. 2004; Dwivedi } \\
\text { et al. 2009; Oliveira et al. } \\
2014\end{array}$} & THR1 & $\begin{array}{l}\text { The information on the AR system is always easy to } \\
\text { see/read. }\end{array}$ \\
\hline & & THR2 & $\begin{array}{l}\text { The battery of the AR systems lasts for at least one } \\
\text { working day. }\end{array}$ \\
\hline \multirow[t]{2}{*}{$\begin{array}{l}\text { Technology } \\
\text { Compatibility }\end{array}$} & \multirow[t]{2}{*}{$\begin{array}{l}\text { Dwivedi et al. 2009; Veile } \\
\text { et al. } 2018\end{array}$} & TC1 & $\begin{array}{l}\text { The AR solution was compatible with the existing IT } \\
\text { infrastructure (e.g. ERP, MRP systems). }\end{array}$ \\
\hline & & TC2 & $\begin{array}{l}\text { There were no health and safety issues concerning the } \\
\text { usage of AR. }\end{array}$ \\
\hline \multirow[t]{4}{*}{ Organisational fit } & \multirow[t]{4}{*}{$\begin{array}{l}\text { Zhu et al. 2010; Yeh et al. } \\
2018\end{array}$} & OF1 & $\begin{array}{l}\text { The management believed in the AR solution during the } \\
\text { implementation phase. }\end{array}$ \\
\hline & & OF2 & The users were involved in the implementation project. \\
\hline & & OF3 & $\begin{array}{l}\text { The users of AR devices were educated about AR during } \\
\text { the implementation process. }\end{array}$ \\
\hline & & OF4 & $\begin{array}{l}\text { The process supported by AR was adapted to fit the } \\
\text { new technology. }\end{array}$ \\
\hline \multirow[t]{4}{*}{ External support } & \multirow[t]{4}{*}{$\begin{array}{l}\text { Zhu et al. 2010; Veile et } \\
\text { al. } 2018\end{array}$} & ES1 & $\begin{array}{l}\text { The vendor of the AR system provided valuable } \\
\text { assistance during the implementation stage. }\end{array}$ \\
\hline & & ES2 & $\begin{array}{l}\text { Other companies that already used AR were consulted } \\
\text { before or during implementation of the AR system. }\end{array}$ \\
\hline & & ES3 & $\begin{array}{l}\text { Industry associations were consulted before or during } \\
\text { implementation of the AR system. }\end{array}$ \\
\hline & & ES4 & The AR solution was based on industry-wide standards. \\
\hline
\end{tabular}

